\title{
Estradiol-treated female mice as surrogate hosts for Neisseria gonorrhoeae genital tract infections
}

\section{Ann E. Jerse*, Hong Wu, Mathanraj Packiam, Rachel A. Vonck, Afrin A. Begum and Lotisha E. Garvin}

Department of Microbiology and Immunology, F. Edward Hebert School of Medicine, Uniformed Services University, Bethesda, MD, USA

\section{Edited by:}

Cynthia N. Cornelissen, Virginia

Commonwealth University School of

Medicine, USA

Reviewed by:

Wenxia Song, University of Maryland,

USA

Roger Rank, Arkansas Children's

Hospital Research Institute, USA

\section{*Correspondence:}

Ann E. Jerse, Department of

Microbiology and Immunology,

Uniformed Services University of the

Health Sciences, 4301 Jones Bridge

Road, Bethesda, MD 20814-4799,

USA.

e-mail: ajerse@usuhs.mil
Historically, animal modeling of gonorrhea has been hampered by the exclusive adaptation of Neisseria gonorrhoeae to humans. Genital tract infection can be established in female mice that are treated with $17 \beta$-estradiol, however, and many features of experimental murine infection mimic human infection. Here we review the colonization kinetics and host response to experimental murine gonococcal infection, including mouse strain differences and evidence that IL-17 responses, toll-like receptor 4 , and $T$ regulatory cells play a role in infection. We also discuss the strengths and limitations of the mouse system and the potential of transgenic mice to circumvent host restrictions. Additionally, we review studies with genetically defined mutants that demonstrated a role for sialyltransferase and the MtrC-MtrD-MtrE active efflux pump in evading innate defenses in vivo, but not for factors hypothesized to protect against the phagocytic respiratory burst and $\mathrm{H}_{2} \mathrm{O}_{2}$-producing lactobacilli. Studies using estradiol-treated mice have also revealed the existence of non-host-restricted iron sources in the female genital tract and the influence of hormonal factors on colonization kinetics and selection for opacity (Opa) protein expression. Recent work by others with estradiol-treated mice that are transgenic for human carcinoembryonic adhesion molecules (CEACAMs) supports a role for Opa proteins in enhancing cellular attachment and thus reduced shedding of $N$. gonorrhoeae. Finally we discuss the use of the mouse model in product testing and a recently developed gonorrhea chlamydia coinfection model.

Keywords: Neisseria gonorrhoeae, mouse, neutrophils, antimicrobial peptides, immune response, hormones, lactobacilli, Opa proteins

\section{INTRODUCTION}

The success of Neisseria gonorrhoeae (Gc) as a pathogen stems from the evolution of several sophisticated adaptation mechanisms that maintain its sole reservoir on the mucosae of infected humans. Some of these mechanisms are sex-specific and in the case of female infection, their evolution appears to be shaped by hormonal influences. Gc is also a genetically flexible pathogen that utilizes phase and antigenic variation to evade or capitalize upon host factors (Simms and Jerse, 2005) and the immunobiology of gonorrhea is both fascinating and puzzling due to the persistence of this organism during intense inflammation and the efficiency by which gonorrhea is transmitted to naïve and previously infected individuals (Sparling, 1999). Continued studies of the pathogenesis of this organism is therefore a rich field of investigation that can benefit from animal modeling to allow testing of hypotheses in the context of an intact host. Translational research is also needed to meet the pressing need for new prophylactic and therapeutic strategies against gonorrhea (Tapsall, 2009; Lewis, 2010).

Historically, animal modeling of Gc infections has been challenged by several host restrictions. However, the use of estradioltreated mice as surrogate hosts for Gc has partially fulfilled the need for an animal model of Gc genital tract infection. Here we describe the characteristics and limitations of experimental murine infection, the potential of transgenic mice to improve the mouse system, and information gained thus far on Gc adaptation to the female genital tract using this model. We also briefly discuss the use of this model in developing vaccines and vaginal microbicides against gonorrhea and describe a newly developed female mouse model of gonorrhea chlamydia coinfection for pathogenesis studies and developing products against pelvic inflammatory disease (PID).

\section{ANIMAL MODELING OF GONOCOCCAL INFECTIONS}

In the 1970s and 1980s, much effort was invested toward developing animal models of Gc infection. Genital tract infection was only successful in chimpanzees (Arko, 1989), which are no longer used for gonorrhea research due to their enormous cost and limited availability. Fortunately, a clue as to the role of the murine estrous cycle in inhibiting Gc colonization came from the discovery that female mice can be colonized when challenged during the proestrus stage of the estrous cycle. Gc is cleared upon transition into the postovulatory stages, and because the estrous cycle lasts only 4-6 days, Gc is recovered for only a few days (Streeter and Corbeil, 1981; Braude, 1982; Johnson et al., 1989). In 1990, Taylor-Robinson et al. (1990) described the use of $17 \beta$-estradiol to promote long-term colonization of germ-free BALB/c mice with Gc. Ten years later we confirmed Taylor-Robinson's report and developed a protocol in which long-term Gc infection can be established in estradioltreated BALB/c mice given antibiotics to suppress the overgrowth of commensal flora that occurs under the influence of estrogen (Jerse, 1999; Song et al., 2008; Figure 1A).

The susceptibility of rodents to human genital tract pathogens is often linked to the estrous cycle and the use of steroid hormones to promote susceptiblity to Gc is consistent with other mouse models of sexually transmitted infections (STIs; Furr et al., 1989; Zeitlin 


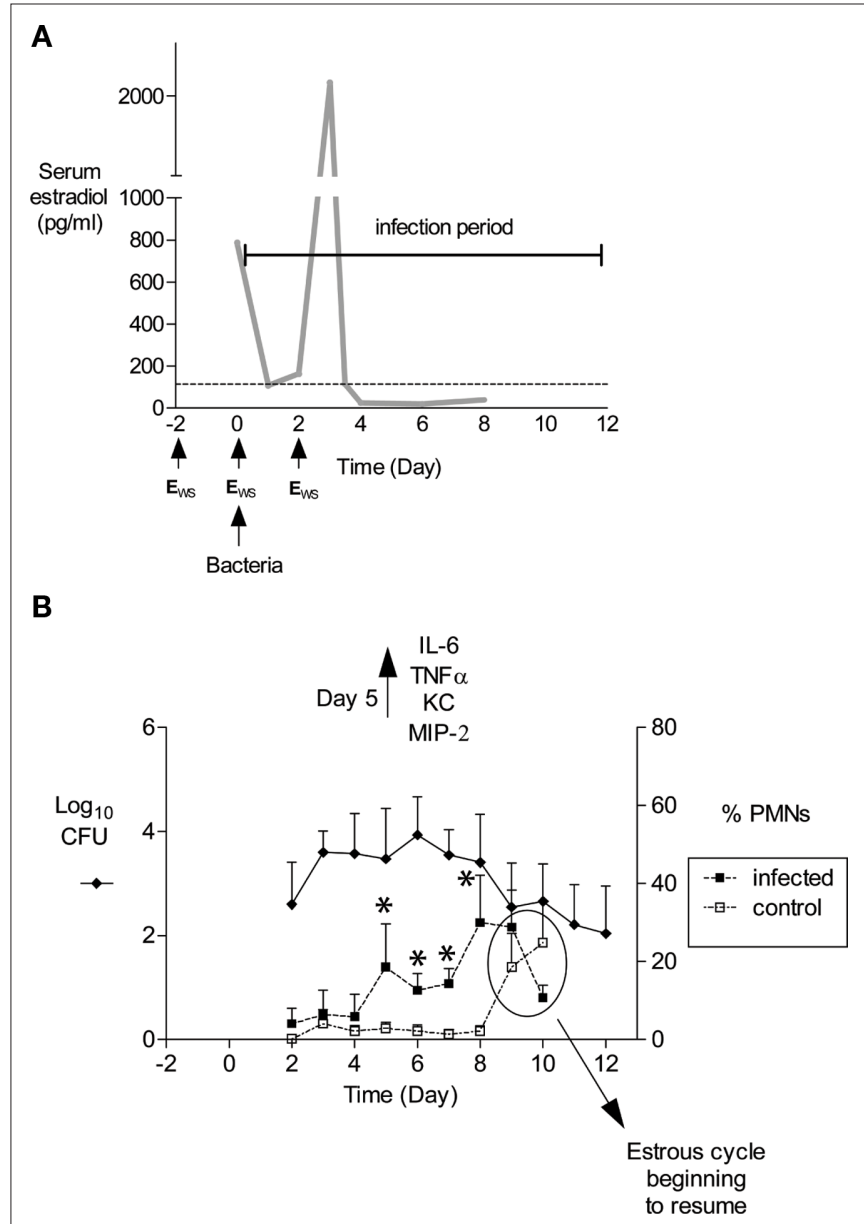

FIGURE 1 | Schematic of mouse infection protocol and characteristics of infection. (A) In our laboratory, mice are treated with $17 \beta$-estradiol to promote Gc infection by implantation of a slow-release pellet under their skin (Jerse, 1999; not shown) or subcutaneous administration of water-soluble estradiol (estradiol ${ }_{\text {ws }} ; 0.5 \mathrm{mg}$ ) on days $-2,0$, and 2 (Song et al., 2008). The benefit of using estradiol ${ }_{\text {ws }}$ is that serum estradiol concentrations return to physiological levels within $24 \mathrm{~h}$ after administration, and in our treatment protocol, Gc is not exposed to abnormal levels by day 3 of infection as shown. The dotted line corresponds to estradiol levels in normal proestrus stage mice (Dalal et al., 2001) Mice are inoculated with bacteria on day 0 . Not shown is the antibiotic treatment regimen, which has been adjusted over time due to changes in breeders and husbandry practices. Currently, streptomycin sulfate (Sm; $2.4 \mathrm{mg}$ ) and vancomycin hydrochloride $(0.4 \mathrm{mg})$ are administered via intraperitoneal (i.p.) inoculation twice daily until day 2 of the infection period. Drinking water with trimethoprim sulfate $(0.04 \mathrm{~g} / 100 \mathrm{ml}$ water $)$ is used over the course of the experiment, with $\mathrm{Sm}(0.5 \mathrm{~g} / 100 \mathrm{ml}$ water $)$ added on day 2 of the infection period. (B) An example of the average number of CFU recovered from a single vaginal swab suspended in $100 \mu \mathrm{l}$ of PBS (left axis) and percent of PMNs in stained vaginal smears (right axis) is shown. Mice $(n=6)$ in this experiment were inoculated with $10^{6}$ CFU of strain FA1090. In published (Packiam et al., 2010) and unpublished data from our laboratory, increased levels of proinflammatory cytokines and chemokines are detected on day 5 of infection as shown, which corresponds to the influx of PMNs in infected mice. Asterisks denote time points at which the percentage of PMNs in infected mice (dashed lines, solid squares) was significantly higher than that in mice given PBS (dashed lines, open squares). Increased PMNs were observed in control mice on days 9 and 10 , which is due to the effects of the estradiol wearing off and the resumption of the estrous cycle. Mice were colonized for an average of 9.9 days in this 12-day experiment. This figure was constructed with combined data reported in (Song et al., 2008; Packiam et al., 2010). et al., 2001; Darville et al., 2003; McGowin et al., 2009) and vaginal candidiasis (Fidel et al., 2000). The reason $17 \beta$-estradiol promotes susceptibility to Gc in mice is not known. The histology and physiology of the genital tracts of estradiol-treated mice mimic the most hospitable stages of the estrous cycle for Gc and estradiol suppresses the natural influx of polymorphonuclear leukocytes (PMNs) that occurs after ovulation. Estradiol is also likely to dampen the inflammatory response based on its immunosuppressive effect on cytokine production (Straub, 2007) or may alter the concentrations of innate receptors and effectors known to be influenced by reproductive hormones (Li et al., 2002; Yao et al., 2007).

\section{CHARACTERISTICS OF MURINE GENITAL TRACT INFECTION LOCALIZATION OF INFECTION AND COLONIZATION KINETICS}

Using the protocols we have described, Gc is recovered from the lower genital tracts of estradiol-treated BALB/c mice for an average of 12 days in a 14-day period and as long as 40 days when slowrelease estradiol pellets are used, and for an average of 10 days when three injections of water-soluble estradiol are given (Jerse, 1999; Jerse et al., 2002; Song et al., 2008). Gc is localized in the vaginal lumen and within vaginal and cervical tissue, including the lamina propria (Song et al., 2008). Endometrial cultures are positive in $17-20 \%$ of mice (Jerse, 1999), a rate that is similar to that reported for ascended cervical infections in women (Hook and Holmes, 1985). This rate may be dose-dependent and actually higher based on the detection of Gc in endometrial tissue by confocal fluorescent microscopy (Imarai et al., 2008). Mouse-passaged strains are not required for murine infection and in early experiments, did not show an enhanced capacity to colonize (Jerse, 1999).

Following inoculation of $\mathrm{BALB} / \mathrm{c}$ mice with $10^{6} \mathrm{CFU}$ of $\mathrm{Gc}$ strains FA1090 or MS11, the average number of Gc recovered from a single vaginal swab ranges from $10^{1}$ to $10^{6} \mathrm{CFU}$ with most cultures yielding $10^{3}-10^{5} \mathrm{CFU}$ (Figure 1B; Jerse, 1999; Jerse et al., 2002; Soler-Garcia and Jerse, 2007; Song et al., 2008). Periods of dramatically reduced recovery or negative cultures are observed followed by a marked increase in recovery in $60-80 \%$ of $\mathrm{BALB} / \mathrm{c}$ mice inoculated with Gc strains FA1090 or 1291 (Jerse, 1999; Simms and Jerse, 2006; and O. Jones-Nelson and Jerse, unpublished observations). We refer to these periods of reduced recovery as culture negative windows or the mid-phase of infection. (Jerse, 1999; Simms and Jerse, 2006) and have evidence that this pattern is hormonally regulated (Cole et al., 2010). It is critical that researchers who use this model be aware of fluctuations in colonization levels, particularly when measuring the effect of a particular host response on clearance or testing the efficacy of vaccines or therapeutic products. We obtain negative cultures for five consecutive days from mice that appear to have resolved infection before concluding infection has cleared. It is also important to understand that the estrous cycle will resume as the effects of the estradiol wear off, and mice will re-gain their natural resistance to infection upon transition into the luteul phase (Figure 1B). Additional doses of estradiol can be administered to prolong infection further.

\section{HOST RESPONSE TO INFECTION}

Gonorrhea in women is characterized by a mucopurulent cervical discharge with numerous PMNs or it can be asymptomatic with over $50 \%$ of women reporting no symptoms (Hook and Holmes, 
1985).Approximately $50 \%$ of infected BALB/c mice (range 30-80\%) have a higher percentage of PMNs in stained vaginal smears on days 4-5 compared to uninfected control mice (Jerse, 1999; Jerse et al., 2002; Soler-Garcia and Jerse, 2007; Packiam et al., 2010), and significantly more PMNs are detected within vaginal and cervical tissue from infected mice on days 2 and 5 post-inoculation. (Song et al., 2008). Localized production of proinflammatory cytokines and chemokines IL-6, TNF $\alpha$, KC, and MIP-2 is significantly increased on day 5 of infection, with MIP-2 expression positively correlating with PMN influx (Packiam et al., 2010; Figure 1B).

Mouse strain differences in susceptibility and host response have been documented. Like BALB/c mice, estradiol-treated CD1, SLC::ddY (Jerse, 1999), and C57BL/6 mice are susceptible to infection. Interestingly, Gc do not elicit an innate inflammatory response in $\mathrm{C} 57 \mathrm{BL} / 6$ mice despite being colonized to similar levels as BALB/c mice (Packiam et al., 2010). C57BL/6 mice therefore appear to mimic asymptomatic infection and perhaps can be used to better define the pathways that lead to or suppress the inflammatory response to Gc. Known differences between C57BL/6 and $\mathrm{BALB} / \mathrm{c}$ mice include the absence of phospholipase A2 in C57BL/6 mice (Kennedy et al., 1995), which may play a role in generating lipid mediators (Kudo and Murakami, 2002) and inducing proinflammatory cytokines and chemokines (Granata et al., 2005). Interestingly, estradiol-treated $\mathrm{C} 3 \mathrm{H} / \mathrm{HeN}$ mice are resistant to $\mathrm{Gc}$ (Packiam et al., 2010) and untreated C3H/HeN mice are also less susceptible to transient Gc colonization following intrauterine inoculation (Streeter and Corbeil, 1981). The natural resistanceassociated macrophage protein (Nramp1) is responsible for the resistance of $\mathrm{C} 3 \mathrm{H} / \mathrm{HeN}$ mice against pathogens that are highly adapted for life within macrophages (Forbes and Gros, 2001). The impact of Nramp1 on susceptibility to Gc infection is not known.

A significant advance in understanding the immune response to Gc was made recently by Mike Russell's laboratory who showed Gc induces IL-17 responses and that secretion of IL-6, LIX, and MIP-2 $\alpha$ is dependent on IL-17 receptor signaling. Importantly, inhibition of IL-17-induced responses in mice via antibody-mediated depletion of IL-17 or infection of IL-17 receptor knock-out mice resulted in increased recovery of bacteria and a significantly longer duration of infection compared to control mice (Feinen et al., 2010). The relevance of this finding to IL-17 responses in humans is supported by the recent report that levels of serum IL-17A and IL-23, which plays a role in the differentiation and proliferation of Th-17 cells, were elevated in patients with Gc urethritis or pharyngitis compared to healthy control subjects (Gagliardi et al., 2011). IL-17, along with IL-22, play a role in inducing antimicrobial peptides in epithelial cells (Kolls et al., 2008). Evidence that Gc induces IL-17 via endotoxin-mediated signaling through toll-like receptor 4 (TLR4; Feinen et al., 2010) may therefore provide a new angle for the design of preventive therapies.

There are many unresolved questions regarding the adaptive humoral response to Gc, which is not protective in humans and appears to be immunosuppressed. While there is some evidence of protective immunity in individuals with repeated exposure, humans can be reinfected with the same strain or serovar and antibody titers are not remarkable and decline over time (Sparling, 1999; Russell and Hook, 2008). Mice also develop a transient and insignificant humoral response to infection and there was no evidence of a humoral memory response or reduced infection in mice that were previously infected with the same strain compared to naïve age-matched, estradiol-treated control mice (Song et al., 2008). Imarai et al. (2008) investigated the basis for the lack of a humoral response to Gc using the mouse system. Gc were detected in endometrial tissue from estradiol-treated BALB/c mice for as long as 22 days and importantly, significantly higher numbers of TGF- $\beta 1^{+} \mathrm{CD} 4^{+} \mathrm{T}$ cells and a subset of $\mathrm{CD} 4^{+} \mathrm{CD} 25^{+}$Foxp $3^{+} \mathrm{T}$ cells were detected in the regional lymph nodes of infected mice compared to control mice. Increased infiltration of TGF- $\beta 1^{+} \mathrm{CD} 11 \mathrm{~b}^{+}$ macrophages into the genital tracts of infected mice also occurred, which could favor the differentiation of $\mathrm{T}$ regulatory cells, and thereby suppress immune responses against Gc (Imarai et al., 2008).

\section{LIMITATIONS OF USING MICE TO STUDY GONOCOCCAL INFECTIONS GENITAL TRACT PHYSIOLOGY}

Several similarities and differences exist between the lower genital tracts of female mice and women. Similar factors include reduced $\mathrm{O}_{2}$ tension, the presence of glucose and lactate (Exley et al., 2007), and cytidine monophosphate $\mathrm{N}$-acetylneuraminic acid (CMPNANA; Wu and Jerse, 2006) used to sialylate the Gc surface during infection. The average vaginal $\mathrm{pH}$ of estradiol-treated female mice is pH 6.6 (range 5.8-7.2; Muench et al., 2009). This $\mathrm{pH}$ is higher than human vaginal $\mathrm{pH}$ (average $\mathrm{pH} 3.5-4.5$ ) but similar to human cervical $\mathrm{pH}$ [proliferative stage, average 6.8 (5.5-8.0); secretory stage, average 6.1 (range 5.1-8.4)] (Singer, 1975), which is the primary site of infection in women. Hormonally driven changes in mucus viscosity, commensal flora (Braude, 1982), and histology (Corbeil et al., 1985) are similar to that which occurs in the human reproductive cycle. A major difference is the fact that there is no period of menstrual bleeding in mice that brings proteases, hemoglobin, and other serum factors into the reproductive tract. Fewer anaerobes colonize the murine genital tract compared to the normal microbiota of most women of reproductive age (Noguchi et al., 2003), but Gram-positive and Gram-negative facultatively anaerobic flora are present. The use of antibiotics to reduce potentially inhibitory commensal flora in the protocols we have described eliminates bacteria of the Enterobacteriaceae and Pseudomonas familes and most Gram-positive flora. Some mice remain colonized with Grampositive organisms, particularly when vancomycin is not used, and vaginal lactobacilli are frequently isolated (Jerse et al., 2002).

\section{HOST RESTRICTIONS AND TRANSGENIC MICE Colonization receptors}

Gc expresses several ligands that bind to specific receptors to mediate adherence or uptake by epithelial cells. At least three of these receptors are host-restricted. Colonization pili are expressed by the vast majority of human isolates (Kellogg et al., 1963); in contrast, murine vaginal isolates lose the piliated colony morphology over time (Jerse, 1999). Mice probably lack the pilus colonization receptor, although its identity is unresolved. Human membrane cofactor protein (CD46) is hypothesized by some to serve as the neisserial pilus receptor (Kallstrom et al., 1997, 2001) and the demonstration that pilus-mediated interactions with CD46 trigger cellular responses through Src kinase-dependent phosphorylation (Lee et al., 2002; Weyand et al., 2009) suggests CD46 has an immunoregulatory role during infection. $\mathrm{CD} 46^{+}$transgenic mice support 
meningococcal dissemination to the brain following intranasal or intraperitoneal inoculation and induce higher levels of cytokines (Johansson et al., 2003, 2005). The impact of CD46 expression on Gc infection of mice has not been reported.

The human CR3 (hCR3) integrin is utilized by Gc to invade primary cervical cells via the binding of pili, LOS, and iC3b (Edwards et al., 2002). The hCR3 molecule has a high degree of similarity to murine CR3; however, it appears to be host-restricted based lack of staining with a hCR3-specific monoclonal antibody that blocks Gc invasion of human cells (unpublished data in collaboration with Drs. Jennifer Edwards and Michael Apicella). Additionally, Rice and colleagues recently showed human factor $\mathrm{H}(\mathrm{fH})$, which is hostrestricted (Ngampasutadol et al., 2008a), bridges the interaction between the gonococcus and CR3 (Agarwal et al., 2010). Therefore a transgenic mouse model that reproduces this invasion pathway may require the expression of both hCR3 and $\mathrm{fH}$.

Other host-restricted receptors known to be used by Gc to invade epithelial cells include the human carcinoembryonic antigen cellular adherence molecules (CEACAMs) $-1,-5$ and -6 to which the phase variable opacity (Opa) proteins bind and CEACAM-3, through which Opa-mediated uptake by PMNs occurs in the absence of opsonization. Opa-CEACAM-1 binding causes immunosuppression of T cells and killing of B cells (Sadarangani et al., 2011). CEACAM transgenic mice are available (Eades-Perner et al., 1994; Bhattacharya-Chatterjee et al., 2008) and CEACAM-5 transgenic mice were recently used by Christof Hauck's laboratory to demonstrate a novel role for Opa-CEACAM interactions in preventing detachment of infected epithelial cells via enhancement of integrinmediated cell to cell adhesion and cellular adhesion to extracellular matix. CEACAM-5 transgenic mice had a higher colonization load than normal mice 1 day after inoculation. This finding supports the interesting hypothesis by this group that CEACAM-engaging bacteria subvert shedding from mucosal surfaces (Muenzner et al., 2005, 2010). Additional studies with CEACAM transgenic mice are needed to demonstrate the Opa-CEACAM invasion pathway during female genital tract infection and test the role of Opa proteins as immunosuppressive factors in vivo. Also, the importance of Opa-CEACAM-3 mediated uptake by PMNs relative to opsonic uptake during cervical infections, where complement is present in the absence of inflammation, is an interesting question that could potentially be addressed using complement depletion of CEACAM-3 transgenic mice.

Gc that express the lacto- $N$-neotetraose (LNT) species of LOS invade through the asialoglycoprotein receptor of primary urethral cells from men. This pathway is sex-specific (Edwards and Apicella, 2004) and thus unlikely relevant to animal modeling of female infections. Other less characterized adhesins and invasins have been described including OmpA, which mediates invasion of immortalized human endocervical and endometrial cells. Interestingly, an ompA mutant was attenuated for murine infection. OmpA was also required for uptake or survival within cultured murine macrophages and whether the observed attenuation in vivo was due to a colonization versus survival advantage is not known (Serino et al., 2007). P1A strains undergo porin-mediated invasion through Gp96 and scavenger receptor SREC. This pathway is phosphatedependent and not restricted to human cells (van Putten et al., 1998; Kuhlewein et al., 2006; Rechner et al., 2007). Gc also invades human cervical cells that do not express CEACAMs (Swanson et al., 2001) and $\mathrm{Opa}^{-}$variants are more invasive than $\mathrm{Opa}^{+}$variants in some systems (Song et al., 2000). The identification of bacterial ligands and receptors used during murine infection is handicapped by the lack of immortalized murine cervical or endometrial cell lines. Adherence and invasion pathway(s) exist for murine infection based on the visualization of Gc associated with genital tract cells (Jerse, 1999) and within mouse tissue (Song et al., 2008) and the detection of intracellular Gc in endometrial cells from murine uterine explant cultures (Imarai et al., 2008).

\section{Iron-binding glycoproteins}

The capacity of Gc to obtain iron from transferrin (Tf) and lactoferrin (Lf) through specific receptors is also host-restricted (Lee and Schryvers, 1988). Expression of either the Tf or Lf receptor was critical for urethral infection of male subjects (Cornelissen et al., 1998; Anderson et al., 2003), but the absence of these receptors or the hemoglobin receptor, which is not host-restricted (Stojiljkovic et al., 1996) does not confer a growth disadvantage in estradioltreated mice (Jerse et al., 2002). Usable iron sources in the female genital tract include siderophores produced by commensal flora (Mickelsen et al., 1982; Carson et al., 1999; Strange et al., 2010), hemin, and ferritin from dying epithelial cells, which are rapidly turned over during the course of the reproductive cycle (Schryvers and Stojiljkovic, 1999), and iron complexed to citric acid, oxalic acetate, pyrophosphate, nitrilotriacetate, or other metabolites (Mickelsen et al., 1982). Additionally, iron is likely to be more soluble in the lower $\mathrm{pH}$ and reduced $\mathrm{O}_{2}$ tension of the female genital tract and thus more available to Gc. A transgenic hTf mouse strain was recently used as an improved model of $N$. meningitidis septicemia from which meningococci were recovered for a longer period and at a 100-fold higher concentration compared to wild type mice (Zarantonelli et al., 2007). The use of hTf transgenic mice may also significantly increase Gc genital tract colonization and perhaps support Gc infection of other body sites. However, the capacity of Gc to replicate in normal mice is direct evidence that non-host-restricted iron stores exist in the female lower genital tract.

\section{Complement regulatory proteins}

Gc that show inherently high levels of porin-mediated resistance to normal human serum bind the soluble regulatory proteins $\mathrm{C} 4 \mathrm{~b}$ binding protein (C4BP; Ram et al., 2001) and factor $\mathrm{H}$ (for strains of the P1A serotype; Ram et al., 1998) to down-regulate the classical and alternative pathways, respectively. Rice and colleagues showed that only human or chimpanzee fH and C4BP bind serum resistant strains, and the generation of hC4BP and/or hfH transgenic mice therefore holds promise for testing the importance of porinmediated serum resistance during female genital tract infection (Ngampasutadol et al., 2008b). Due to the role that complement activation plays in inducing cytokines and chemokines and the adaptive response (Dunkelberger and Song, 2010) such mice would also be a valuable resource for studying the host response to infection.

\section{IgA1}

Like many human-specific mucosal pathogens, Gc produces an IgA1 protease that cleaves only primate IgA1 (Qiu et al., 1996). How important IgA1 protease is for infection is not known. Russell and 
colleagues found no evidence of IgA cleavage products in cervical fluid from women with gonorrhea (Hedges et al., 1998), and IgA2 presumably can serve as a redundant protective factor. An IgA1 protease mutant was not attenuated for urethral infection of naïve male volunteers (Johannsen et al., 1999), although its importance in previously infected subjects cannot be ruled out. Attenuation of an IgA1 protease mutant of Streptococcus pneumoniae in a mouse septicemia model (Polissi et al., 1998) suggests non-host-restricted roles exist for this class of enzymes. Gc IgA1 protease cleaves a phagosomal maturation protein to promote increased survival and transit through polarized epithelial cells (Lin et al., 1997; Hopper et al., 2000) and may modulate the host response based on the reported inhibition of apoptosis of immune cells and induction of proinflammatory cytokines by purified IgA1 protease in vitro (Lorenzen et al., 1999; Beck and Meyer, 2000). Whether these interactions are host-restricted has not been reported.

\section{PATHOGENESIS STUDIES}

Gc encounters a variety of innate defenses in the female genital tract, some of which are illustrated in Figure 2A. The testing of bacterial mutants in factors that are hypothesized to promote Gc survival in vivo has confirmed predictions from in vitro studies and generated new information that may be relevant to lower genital tract infection in women, particularly with regard to evasion of phagocytes, antimicrobial peptides, and commensal bacteria and adaptation to hormonally regulated factors (Figure 2B).

\section{SIALYLTRANSFERASE BUT NOT ANTI-OXIDANT FACTORS PROTECT AGAINST PMNS}

Gc is superbly adapted for evasion PMNs in which they survive and perhaps replicate (Casey et al., 1979; Simons et al., 2005; Criss et al., 2009). Examination of PMN killing mechanisms in the mouse system has the advantage of reproducing natural pathways of PMN recruitment and activation and physiologically relevant concentrations of iron, oxygen, and glucose needed to fuel the oxidative burst (Storz et al., 1990) and CMP-NANA, which when added to gonococcal LNT LOS via the action of $\alpha-2,3$-sialylatransferase (Lst), increases resistance to complement-mediated uptake by PMNs (Smith et al., 1995; Gill et al., 1996). Additionally, PMNs from estradiol-treated mice produce a dose-dependent oxidative burst when exposed to Gc that is primarily intracellular (SolerGarcia and Jerse, 2007) as reported for human PMNs (Naids and Rest, 1991; Simons et al., 2005). Limitations include differences in the concentrations of myeloperoxidase and other granular enzymes

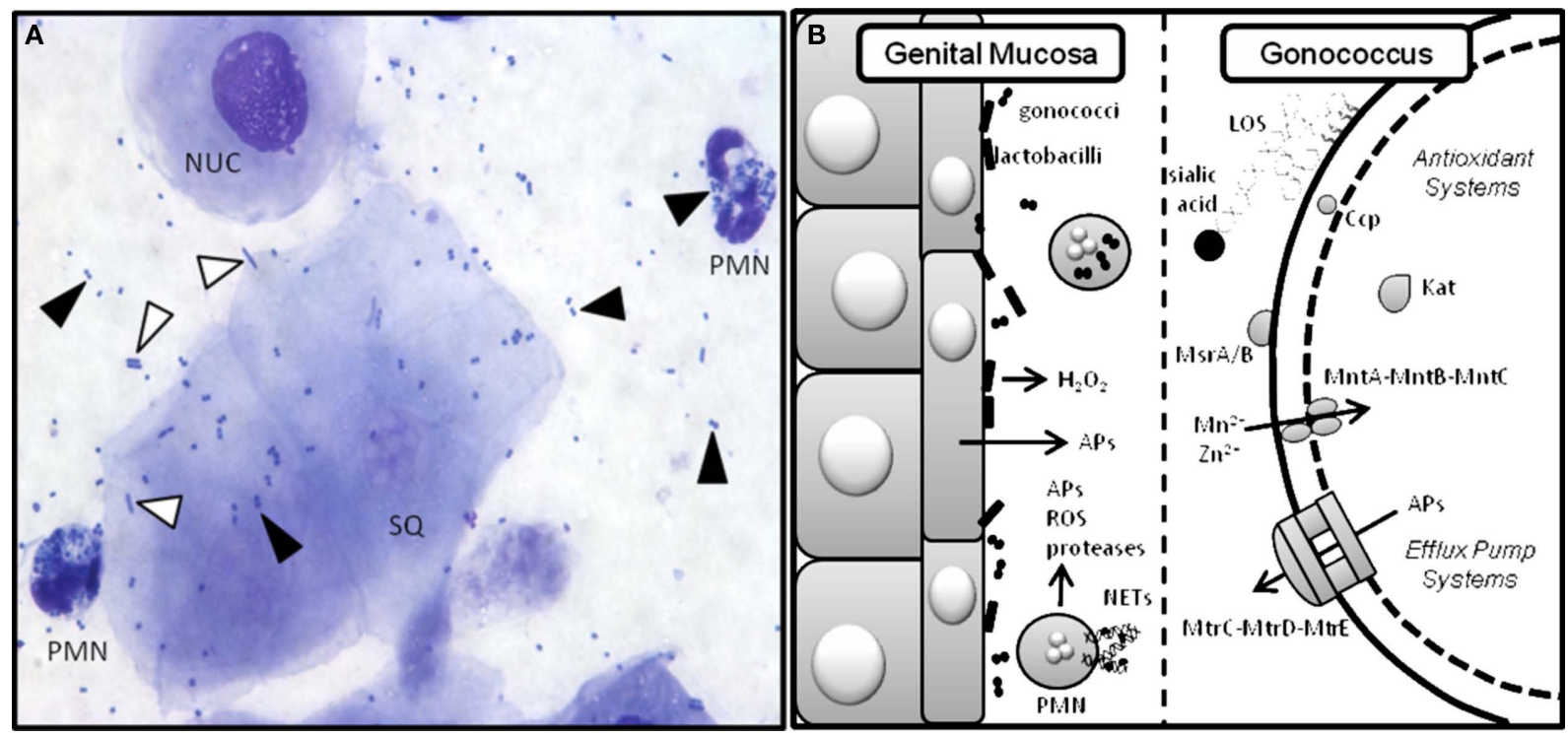

FIGURE 2 | Gc interactions with innate defenses in the murine genital tract. Gc encounters a variety of innate defenses in the female genital tract including hydrophobic antimicrobial substances that bathe the mucosal surface,

complement, and commensal flora (Boris and Barbes, 2000). Pathogen-induced activation of innate receptors on epithelial and immune cells causes secretion of antimicrobial peptides and proinflammatory cytokines and chemokines (Kolls et al., 2008), which recruit phagocytes to the infection site. PMNs can take up bacteria that are opsonized with complement deposition products. Phagocyteproduced reactive oxygen species (ROS) kill bacteria by damaging DNA, protein, and other macromolecular structures (Storz et al., 1990). PMNs also kill microbes via the release of pre-formed enzymes and antimicrobial peptides and entrapment in neutrophil extracellular traps (NETs) where they are exposed to toxic molecules produced by both pathways (Kobayashi et al., 2005;

Papayannopoulos and Zychlinsky, 2009). (A) Stained vaginal smear from a Gc-infected mouse reveals the presence of nucleated (NUC) and squamous
(SQ) epithelial cells and PMNs with intracellular diplococci. Black arrows denote $\mathrm{Gc}$ and white arrows denote lactobacilli. Human strains of $\mathrm{H}_{2} \mathrm{O}_{2}$-producing lactobacilli can be added to this ecosystem as described (Muench et al., 2009). (B) Cartoon depicting the murine genital mucosa on the left and some of the bacterial factors that have been tested to measure their role in protection from host innate defenses on the right. Gc has many redundant anti-oxidant systems including $\mathrm{C}_{\mathrm{cp}}$ (cytochrome c peroxidase), Kat (catalase), MsrA/B (a methionine sulfoxide reductase), and the MntA-MntB-MntC manganese transporter, which do not protect Gc from phagocyte-derived (Kat, Ccp, MntC; Wu et al., 2009), or Lactobacillus-derived (Kat, Ccp) ROS in vivo (Muench et al., 2009). Gc add host sialic acid to their LOS via the action of sialyltransferase. This modification reduces uptake of the bacteria by PMNs and increases survival in vivo (Wu and Jerse, 2006). Antimicrobial peptides (APs) are actively expelled from the cell via the MtrC-MtrD-MtrE efflux pump and inactivation of this system is highly attenuating for murine infection (Jerse et al., 2003). 
in murine and human PMNs (Rausch and Moore, 1975), and the absence of Opa-CEACAM-mediated uptake by PMNs. Although it is possible that estradiol impairs PMN killing, we detect no difference in the killing capacity of PMNs from estradiol-treated versus untreated mice (Soler-Garcia and Jerse, 2007).

There is now much evidence that the oxidative burst of phagocytes does not challenge Gc, including studies with PMNs from humans with chronic granulomatous disease and the use of pharmacological inhibitors of the respiratory burst (Rest et al., 1982; Criss et al., 2009). Infection studies in C57BL/6 mice that have a defective NADPH oxidase (Phox) provided in vivo evidence that phagocytic-derived ROS do not challenge Gc during genital tract infection ( Wu and Jerse, 2006) with the caveat that C57BL/6 mice do not produce a signficant PMN response to Gc infection (Packiam et al., 2010). Whether this host defense is more potent in body sites where oxygen levels are higher such as the pharynx, is not known, but seems unlikely based on PMN killing assays performed under anaerobic versus aerobic conditions (Casey et al., 1986; Frangipane and Rest, 1992).

Perhaps a bigger question is how Gc evades phagocyte-derived ROS. Gc is equipped with a battery of factors that protect it from in vitro exposure to $\mathrm{H}_{2} \mathrm{O}_{2}$ and inducers of intracellular and extraceullar ROS, including the detoxifying enzymes catalase (Kat) and cytochrome $\mathrm{C}$ peroxidase (Ccp), non-enzymatic quenching of $\mathrm{O}_{2}^{-}$ by $\mathrm{Mn}^{2+}$, which is taken up by the manganese transporter MntABC, methionine sulfoxide reductase (MsrA/B), which repairs oxidatively damaged proteins, a thiol-disulfide oxidoreductase (Sco), azurin, bacterioferritin and novel peroxidase-induced genes of unknown function (Seib et al., 2006). This abundance of anti-oxidant mechanisms is impressive, yet there if no evidence that these factors protect $\mathrm{Gc}$ from the vigorous PMN response encountered in vivo. For example, a kat mutant and kat ccp and kat sco mutants of strain 1291 were not more susceptible to killing by human PMNs (Seib et al., 2005). Similarly, single, double, and triple mutants in the kat, $c c p, m s r A B$, and $m n t C$ genes in strain MS11 were not more susceptibile to killing by murine PMNs. These mutants were also not attenuated during infection of normal BALB/c mice or Phox-deficient and Phox-sufficient C57BL/6 mice (Wu et al., 2009). Further genetic stripping of the factors known to protect $\mathrm{Gc}$ from exposure to $\mathrm{H}_{2} \mathrm{O}_{2}$ or inducers of ROS may debilitate Gc against $\mathrm{O}_{2}$-dependent PMN killing. The answer may, however, reside in novel mechanisms that do not involve direct protection from ROS (Lorenzen et al., 2000; Criss and Seifert, 2008; Criss et al., 2009).

Possible new functions for MsrA and MntC were revealed using murine infection. The $m s r A$ mutant showed delayed attenutation in vivo in $\mathrm{BALB} / \mathrm{c}$ mice and because macrophages appear later than PMNs during infection of BALB/c mice (Song et al., 2008) reduced recovery of $m s r A$ mutant may be due to increased sensitivity to macrophage killing as described for other bacteria (St John et al., 2001; Douglas et al., 2004). Additionally, inactivation of $m n t C$ resulted in an attenutated phenotype in normal BALB/c and Phox-deficient and Phox-sufficient C57BL/6 mice. MntC-deficient Gc may be more susceptible to ROS produced by epithelial cells. Inactivation of $m n t C$ may also reduce biofilms, which may be important in stabilizing colonization (Lim et al., 2008).

In contrast to the anti-oxidant factors tested above, Lst plays a detectable role in defending Gc from PMN killing in vitro and in the mouse model. Sialylation of Gc occurs within the first day of murine infection and inactivation of the lst gene confers a survival disadvantage in BALB/c mice. Decreased resistance to PMN killing is the most likely explanation for the observed attenuation based on the greater susceptibility of the lst mutant to opsonophagocytic uptake and killing by murine PMNs in vitro and significantly faster clearance of the lst mutant following intraperitoneal injection compared to sialylated, wildtype bacteria (Wu and Jerse, 2006). LOS also increases resistance to complement-mediated bacteriolysis by enhancing the binding of $\mathrm{fH}$ to P1B porin (Madico et al., 2007). The importance of sialyltransferase in Gc survival is therefore likely underestimated in studies with normal mice due the host restriction for $\mathrm{fH}$. While the host restriction for $\mathrm{fH}$ did not affect opsonophagocytosis at a functionally detectable level in our study, the lst mutant was equally attenuated in normal and C5-deficient mice (Wu and Jerse, 2006). These findings are consistent with the requirement for higher numbers of membrane attack complexes for bacteriolysis than opsonins for phagocytosis. Again, studies in $\mathrm{fH}$ transgenic mice could further illustrate the importance of sialyation in infection.

\section{EVIDENCE OF COMPLEX INTERACTIONS BETWEEN GC AND LACTOBACILLI}

Epidemiological data show an increased risk for gonorrhea in women that lack vaginal lactobacilli, with some studies implicating $\mathrm{H}_{2} \mathrm{O}_{2}$-producing lactobacilli as a defense in particular (Antonio et al., 1999; Wiesenfeld et al., 2003) and others showing the same association regardless of the $\mathrm{H}_{2} \mathrm{O}_{2}$ production phenotype (Saigh et al., 1978; Hillier et al., 1992; Martin et al., 1999). It is not clear whether lactobacilli are directly responsible for the inverse correlation between gonorrhea and vaginal lactobacilli because an absence of lactobacilli is associated with bacterial vaginosis in which an imbalance of other bacteria also occurs (Hillier et al., 1992). $\mathrm{H}_{2} \mathrm{O}_{2}$ producing Lactobacillus sp. inhibit Gc in vitro (Saigh et al., 1978; St Amant et al., 2002), and Gc kat and ccp mutants are more susceptible than wild type Gc. However, surprisingly, there was no difference in the recovery of wild type, kat, or kat ccp mutant Gc from mice that were pre-colonized with $\mathrm{H}_{2} \mathrm{O}_{2}$-producing L. crispatus compared to mice that were not colonized with this human commensal (Muench et al., 2009). L. crispatus makes several factors that could enhance Gc growth or survival, one of which is lactate (Smith et al., 2007). As inactivation of the gonococcal lactate permease $(l c t P)$ gene was attenuating for murine infection (Exley et al., 2007), we hypothesized that utilization of Lactobacillus-produced lactate might balance the detrimental effects caused by Lactobacillus-produced $\mathrm{H}_{2} \mathrm{O}_{2}$ in vivo. However, a kat lctP Gc mutant also colonized mice with $L$. crispatus as well as mice without L. crispatus (Muench et al., 2009).

The murine infection data predict that vaginal $\mathrm{H}_{2} \mathrm{O}_{2}$-producing lactobacilli do protect against $\mathrm{Gc}$, possibly because the $\mathrm{O}_{2}$ tension may not be sufficient for adequate $\mathrm{H}_{2} \mathrm{O}_{2}$ production. However, it is possible that $\mathrm{H}_{2} \mathrm{O}_{2}$ is more stable in the lower $\mathrm{pH}$ of the human vagina or the colonization density of L. crispatus in mice is not sufficiently high. A recent report that human cervical secretions block $\mathrm{H}_{2} \mathrm{O}_{2}$-mediated bactericidal activity however, also suggests Lactobacillus-derived $\mathrm{H}_{2} \mathrm{O}_{2}$ is not a formidable defense against STI pathogens (O'Hanlon et al., 2010). These studies do not rule out a role for other Lactobacillus factors in challenging $N$. gonorrhoeae (Spurbeck and Arvidson, 2010). Such factors may have also been produced by non- $\mathrm{H}_{2} \mathrm{O}_{2}$ producing murine lactobacilli in control 
mice in the mouse study discussed above. Nonetheless, interesting observations have been made while working with the mouse model in our laboratory that suggest Gc has evolved mechanisms to coexist with these commensals. For example, L. murinus, a mouse Lactobacillus sp., supports growth of Gc on solid agar (Jerse et al., 2002) as do $\mathrm{H}_{2} \mathrm{O}_{2}$-producing human Lactobacillus strains if catalase is added, and mice with L. murinus usually have a very high Gc colonization load (A. E. Jerse, unpublished observation).

\section{THE MTRC-MTRD-MTRE ACTIVE EFFLUX PUMP PLAYS AN IMPORTANT ROLE IN EVASION OF HOST DEFENSES}

Gc produces several active efflux pump systems that expel antimicrobial substances from the periplasm. Host-derived substrates expelled by the MtrC-MtrD-MtrE efflux pump system include human cathelicidin LL37, the mouse homolog cathelicidinrelated antimicrobial peptide (CRAMP), progesterone, and fatty acids (Shafer et al., 2001; Jerse et al., 2003; Warner et al., 2008). MtrCDE-deficient mutants are the most attenuated of all mutants tested thus far in the mouse model, which is consistent with a role for this efflux system in protecting against host defenses (Jerse et al., 2003). Inactivation of MtrR and MtrA, which negatively and positively regulate $m t r C D E$ expression, respectively causes a phenotype in mice that is consistent with the importance of the MtrC-MtrD-MtrE efflux pump in infection (Warner et al., 2007). In contrast, the FarA-FarB-MtrE efflux pump system does not have a detectable role in murine infection (Jerse et al., 2003). This system primarily protects Gc from long chain fecal lipids, and thus may be more important during rectal infections (Lee and Shafer, 1999). Infection studies in mice that are deficient in CRAMP (Nizet et al., 2001) may facilitate further investigation of the role of the MtrC-MtrD-MtrE pump in infection; however, the presence of more than one pump substrate may complicate definitive identification of host factors that challenge MtrCDE-deficient Gc in vivo. $m t r E$ mutants are also more sensitive to bactericidal/permeabilityincreasing (BPI) protein (A.A. Begum and A. E. Jerse, unpublished data), which is a lipid A-binding protein that is present in both the human and murine genital tracts (Canny et al., 2006; Eckert et al., 2006). Also, increased susceptibility of MtrCDE-deficient Gc to progesterone in vitro and the faster clearance of MtrCDE-deficient Gc from normal mice versus ovariectomized mice suggests progesterone or progesterone-regulated factors challenge these mutants during infection.

Derepression of the $m t r C D E$ operon through a single base pair deletion in the $m t r R$ promoter region or point mutations in the MtrR structural gene is a mechanism by which Gc strains become resistant to macrolide antibiotics and high levels of penicillin (Shafer et al., 2001). Antibiotic resistance mutations often confer reduced fitness in vitro due to the effect these mutations have on growth. An exception to this paradigm are $m t r R$ locus mutations that confer increased fitness in the mouse model. Commonly isolated $m t r R$ locus mutations confer different levels $m t r C D E$ derepression, which is mirrored by different levels of fitness advantage in vivo (Warner et al., 2008). One might predict that the percentage of $m t r R$ locus mutants would be higher among clinical isolates should the observed fitness benefit in mice hold true for human infection. It may be that the mouse data are not predictive of events during human infection or there are sex-based or anatomical differences in the types of innate effectors that select for $m t r R$ locus mutations. Alternatively, $m t r R$ locus mutants frequently carry more than one antibiotic resistance mutation, which may confer an overall fitness cost (Komp Lindgren et al., 2005).

\section{ADAPTATION TO HORMONALLY REGULATED FACTORS THROUGH OPA GENE PHASE VARIATION}

The neisserial Opa proteins are a family of phase variable outer membrane proteins that are encoded by 10-12 unlinked genes (Simms and Jerse, 2005). Selection for Opa expression during urethral infection occurs in naturally (James and Swanson, 1978) and experimentally infected male volunteers (Swanson et al., 1988; Jerse et al., 1994). Selection for Opa variants in the female genital tract appears more complex, with predominantly opaque $\left(\mathrm{Opa}^{+}\right)$colonies isolated during the proliferative stage of the menstrual cycle and transparent $\left(\mathrm{Opa}^{-}\right)$colonies isolated during or shortly after menses. Based on this intriguing observation, James and Swanson (1978) hypothesized that subpopulations of bacteria are better adapted for different stages of the reproductive cycle. This hypothesis is consistent with reported higher rates of positive cultures from women with gonorrhea during the proliferative stage than the middle secretory stage (Koch, 1947; Johnson et al., 1969; James and Swanson, 1978; McCormack and Reynolds, 1982; Figure 3A).

Interestingly, $\mathrm{Opa}^{+}$variants are isolated from $\mathrm{BALB} / \mathrm{c}$ mice in a cyclical recovery pattern that consists of early $\left(\mathrm{Opa}^{+}\right)$, mid $\left(\mathrm{Opa}^{-}\right)$and late $\left(\mathrm{Opa}^{+}\right)$phases. Consistent with subpopulations of bacteria being cleared or having an advantage, fluctuations in the predominant Opa phenotype recovered are paralleled by changes in the total number of Gc recovered (Simms and Jerse, 2006; Figure 3B). A cyclical recovery pattern also occurs during short-term colonization of mice that are not treated with estradiol. The importance of Opa proteins during the early and late phases was confirmed by the demonstration that an Opa-deficient mutant colonized mice less well than the mutant expressing one functional opa allele during the first day of infection, and unlike the Opa-deficient strain, the $\mathrm{Opa}^{+}$strain was recovered following the mid-phase (Cole et al., 2010). A link between the reproductive cycle and the cyclical recovery pattern was revealed by studies with ovariectomized mice, which select for $\mathrm{Opa}^{+}$variants early in infection and maintain this selection over time. Also, unlike intact (normal) mice, fluctuations in the number of Gc recovered from ovariectomized mice were not observed (Cole et al., 2010). The selective forces responsible for the cyclical changes in Opa phenotype in normal mice must be due to a CEACAM-independent Opa function. Complement was shown to preferentially kill Opa ${ }^{+}$ variants of strain MS11 (Bos et al., 1997) and complement levels in the female human and murine genital tracts are hormonally regulated (Hasty et al., 1994; Li et al., 2002). However, experiments with complement-depleted mice did not support complement as the selective factor (Cole et al., 2010).

The factors that select for $\mathrm{Opa}^{+}$variants during human infections are also not known. In women, CEACAM-mediated adherence to and invasion of cervical cells may select for Opa-expressing variants during infection, as may increased attachment of epithelial cells with adherent bacteria (Muenzner et al., 2005, 2010) as discussed. Based on data from BALB/c mice, we hypothesize that CEACAMindependent factors also exist. CEACAMs were not detected on 


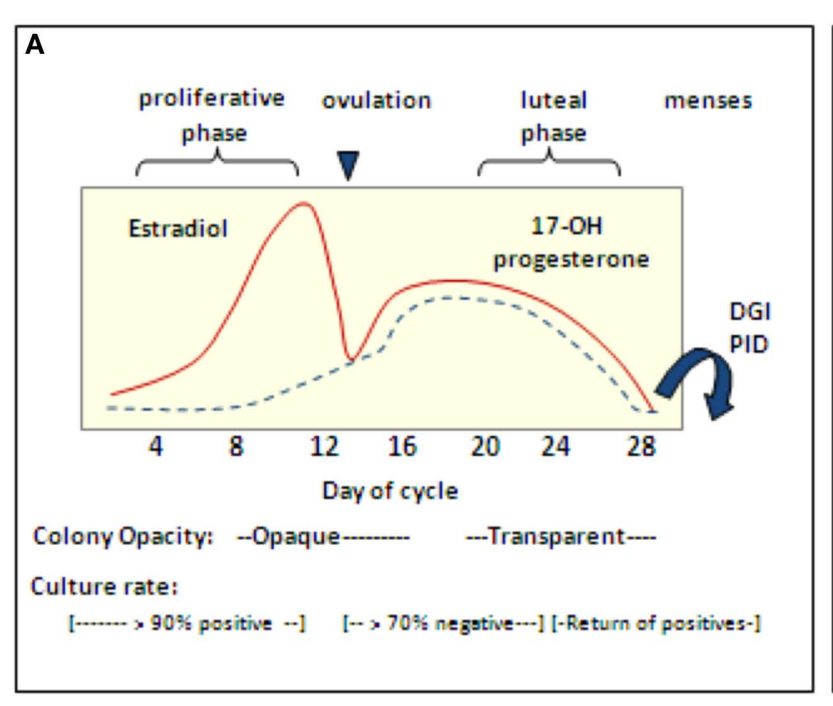

FIGURE 3 |The reproductive cycle influences $\mathrm{Gc}$ infection of women and mice. (A) Culture rates from women with gonorrhea and the opacity phenotype of cervical isolates from infected women with respect to stages of the menstrual cycle (Koch, 1947; Johnson et al., 1969; James and Swanson, 1978; McCormack and Reynolds, 1982). In one study, women with gonorrhea were hospitalized without treatment and in four of four women, positive cultures were followed by five to six consecutive negative cultures during the secretory phase; cultures became positive again at menses (Koch, 1947). Gonococcal PID and disseminated gonococcal infection most frequently occur at or shortly after menses (Holmes et al., 1971) and Gc from fallopian tubes from women with salpingitis were reported to be Opa- (Draper et al., 1980). (B) Cartoon depicting

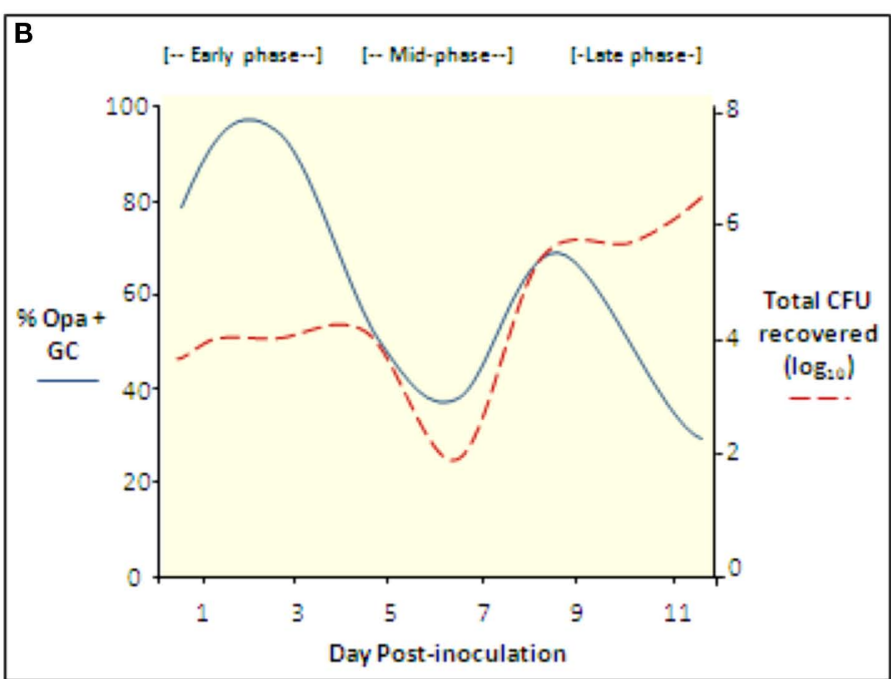

the cyclical recovery pattern seen in intact mice following inoculation with mostly Opa- variants of strain FA1090. Within a day after inoculation with mostly $\mathrm{Opa}^{-} \mathrm{Gc}, \mathrm{Opa}^{+}$variants predominate (early phase). This phase is followed by a period in which mostly Opa- variants are isolated (mid-phase) and then a second $\mathrm{Opa}^{+}$phase (late phase). A high percentage of isolates express multiple Opa proteins in the late phase. In mice that remain infected for more than 8 days, a second mid-phase is observed. The rise and fall of the Opa ${ }^{+}$population corresponds to fluctuations in the total number of $\mathrm{Gc}$ recovered. This pattern is not seen in Ov mice. Hostile factors may reduce colonization during the mid-phase or perhaps $\mathrm{Opa}^{+}$variants are less accessible for culture due to tissue invasion (Simms and Jerse, 2006; Cole et al., 2010). primary urethral cells from men (Edwards and Apicella, 2004) and therefore, the selection of $\mathrm{Opa}^{+} \mathrm{Gc}$ during natural or experimental urethral infection of men may also be due to another factor(s).

The reason for periods of reduced recovery of Gc from female mice and women is also not understood. In women, the capacity of Gc to invade and survive within cervical cells via the host-restricted CR3 pathway is affected by reproductive hormones and therefore, the presence of Gc within intracellular niches may contribute to cyclical culture rates from women (Edwards, 2010). Hormonally driven changes in metalloprotease and cathepsin expression, which function to remodel tissue (Afonso et al., 1997; Jokimaa et al., 2001), could also open avenues for invasion into tissue in mice or women as described for other pathogens (Azghani et al., 2000; Katz et al., 2000) or alter the host response as demonstrated for chlamydial infection using matrix metalloprotease nine knock-out mice (Imtiaz et al., 2007). Up-regulation of anti-Gc effectors during the luteal phase of the cycle may also contribute to selection patterns via hormonal regulation of TLRs (Yao et al., 2007).

\section{FUTURE DIRECTIONS PRODUCT DEVELOPMENT}

Safe and effective therapeutic and prophylactic products against Gc are greatly needed to reduce the incidence of gonorrhea and protect women's reproductive health. Infertility treatment is a significant and hidden cost of ascended infections and ectopic pregnancy causes $4.1 \%$ of maternal-related deaths in industrialized countries (Khan et al., 2006). Gonorrhea is also a cofactor for HIV transmis- sion (Cohen et al., 1997). Alarmingly, the reliance on antibiotic treatment as a control measure is seriously threatened by the rapid emergence of antibiotic-resistant strains (Tapsall et al., 2005). The need for an animal model to facilitate pre-clinical testing of products against gonorrhea was reflected by the numerous academic and industrial collaborators who approached our laboratory upon the first publication of the mouse model. Continued research in this area is critical. Here we briefly describe our experience with testing vaccines and vaginal microbicides in the mouse model with an emphasis on practical considerations and challenges for product development.

\section{Vaccine development}

Successful development of a gonorrhea vaccine faces many challenges as recently reviewed (Zhu et al., 2011). The availability of an animal model for systematic testing of different antigens, immunization strategies, and defining correlates of protection should facilitate vaccine development as should growing information on protective immunological pathways in mice and humans (Imarai et al., 2008; Feinen et al., 2010; Gagliardi et al., 2011). An OMVbased vaccine demonstrated protection against strain MS11 (Plante et al., 2000) but was not successful in subsequent studies or with other strains (Zhu et al., 2011). As of yet, vaccine-induced protection of mice with other antigens has not been reported, although data we have obtained thus far are useful for evaluating the effectiveness of different immunization strategies in inducing local and systemic immune responses. A practical obstacle for vaccine studies 
in the estradiol-treated mouse model is the need to immunize more mice than are actually challenged since only diestrus or anestrus stage mice can be used in the challenge phase of the experiment. Ovariectomized mice can be used to circumvent this problem since they do not need to be staged prior to estradiol treatment. Ovariectomized mice are more expensive, however, and we speculate that their innate responses may be compromised based on the absence of the cyclical recovery pattern in ovariectomized mice as discussed (Cole et al., 2010). Certain host restrictions should especially be considered when testing vaccines for humans. IgA1 protease and restrictions in the complement cascade may most significantly challenge the power of murine infection to predict vaccine efficiacy, particularly against serum resistant strains. The development of hC4BP and $\mathrm{fH}$ transgenic mice should therefore be a useful tool for vaccine testing (Ngampasutadol et al., 2008b). Passive delivery of purified fH or hC4BP could also be used as was recently shown to improve experimental infection of rats by $N$. meningitidis (Granoff et al., 2009).

\section{Vaginal microbicides}

The development of topically applied products for reducing the risk of STIs in women has been a public health priority in recent years. Topical agents that have been tested against Gc in the estradiol-treated mouse model include porphyrin binding proteins (Bozja et al., 2004), formulated natural, and synthetic sulfated and sulfonated polymers [CarraGuard ${ }^{\mathrm{TM}}$, Ushercell, T-PSS, PRO 2000 ${ }^{\mathrm{TM}}$ ], acid-buffering agents [ACIDFORM, BufferGel ${ }^{\mathrm{TM}}$ ], and cellulose acetate phthalate (CAP; Spencer et al., 2004). With the exception of Carraguard, there was good correlation between the in vitro activity of each agent and effectiveness in vivo. Interestingly, CarraGuard prevented infection of mice but did not inhibit Gc in vitro (Spencer et al., 2004). This finding underscores the importance of testing products in an animal model system. Several of these products have since undergone safety and acceptiblity testing in humans (Carraguard, 2010; von Mollendorf et al., 2010).

Many challenges face the assessment of vaginal microbicide effectiveness in humans (Ramjee et al., 2010), but animal modeling can continue to play useful role in the development of these products for screening novel compounds and expanding testing protocols to include the assessment of repeated application of agents, which can affect susceptiblity (Cone et al., 2006). A limitation of the gonorrhea mouse model, like most STI models, is that it is not a transmission model and the bacterial suspension used to inoculate mice does not simulate the bodily fluids that transmit the microbe in terms of $\mathrm{pH}$, biochemical make-up, and the presence of immune effectors and inhibitors of host defenses.

\section{REFERENCES}

Afonso, S., Romagnano, L., and Babiarz, B. (1997). The expression and function of cystatin C and cathepsin B and cathepsin L during mouse embryo implantation and placentation. Development 124, 3415-3425.

Agarwal, S., Ram, S., Ngampasutadol, J. Gulati, S., Zipfel, P. F., and Rice, P. A. (2010). Factor $\mathrm{H}$ facilitates adherence of Neisseria go norrhoeae to complement receptor 3 on eukaryotic cells. J. Immunol. 185, 4344-4353.

Anderson, J. E., Hobbs, M. M., Biswas, G. D., and Sparling, P.F. (2003). Opposing selective forces for expression of the gonococcal lactoferrin receptor. $\mathrm{Mol}$. Microbiol. 48, 1325-1337.

Antonio, M. A., Hawes, S. E., and Hillier, S. L. (1999). The identification of

\section{ANIMAL MODELING OF COINFECTIONS}

An important charactersitic of STIs is the frequency by which more than one pathogen is present. The availability of well characterized models of gonorrhea (Song et al., 2008), chlamydia (Darville et al., 2003), and M. genitalium (McGowin et al., 2009) infection affords the opportunity to develop coinfection models for these three pathogens, which are major causes of PID. As many as 70\% of individuals with gonorrhea have chlamydia (Miller et al., 2004) and we recently developed a gonorrhea chlamydia coinfection model for use as a research tool (Vonck et al., 2011). Significantly more vaginal PMNs were detected in coinfected mice compared to mice infected with either pathogen alone. This result is consistent with the reported higher levels of symptoms in individuals coinfected with Gc and C. trachomatis (Nsuami et al., 2004; Rosenvinge and Lau, 2009). Interestingly, higher numbers of Gc were recovered from coinfected mice compared to mice infected with Gc alone (Vonck et al., 2011). Continued use of the gonorrhea chlamydia coinfection model combined with human-based systems should illuminate the basis for these observations. The development of dually active therapeutic agents should also be accelerated by this model. Such agents are needed to simplify treatment regimens and potentially reduce the costs associated with therapy.

\section{SUMMARY}

The development of the estradiol-treated mouse model of Gc infection has expanded the research tools available for studying Gc genital tract infections. Researchers can now experimentally manipulate the host response and utilize mice that are genetically defective in immunological pathways and effector molecules to inform our understanding of the host response against gonorrhea, as has benefitted the study of many other infectious diseases. The growing availability of transgenic mice should improve the relevance of mice as surrogate hosts for Gc and provide an opportunity to test the biological significance of host-restricted bacterial-host cell interactions observed in vitro. The mouse model is also a useful system for studying hormonal influences on bacterial-host cell interactions, which is an exciting but understudied area. Finally, the mouse model has accelerated product testing, which is greatly needed for gonorrhea, and can be adapted to develop STI coinfection models.

\section{ACKNOWLEDGMENTS}

We thank the numerous collaborators who sent us bacterial strains, vaccine antigens, microbicides, and therapeutic compounds to test in the estradiol-treated mouse model. Their participation has been invaluable in the development of this experimental system for gonorrhea research. This work was supported by NIH/NIAID RO1 AI42053 and U19 AI31496.

vaginal Lactobacillus species and the demographic and microbiologic characteristics of women colonized by these species. J. Infect. Dis. 180, 1950-1956.

Arko, R. J. (1989). Animal models for pathogenic Neisseria species. Clin. Microbiol. Rev. 2(Suppl. ), S56-S59.

Azghani, A. O., Bedinghaus, T., and Klein, R. (2000). Detection of elastase from
Pseudomonas aeruginosa in sputum and its potential role in epithelial cell permeability. Lung 178, 181-189.

Beck, S. C., and Meyer, T. F. (2000). IgA1 protease from Neisseria gonorrhoeae inhibits TNFalpha-mediated apoptosis of human monocytic cells. FEBS Lett. 472, 287-292.

Bhattacharya-Chatterjee, M., Saha, A., Foon, K. A., and Chatterjee, S. K. 
(2008). Carcinoembryonic antigen transgenic mouse models for immunotherapy and development of cancer vaccines. Curr. Protoc. Immunol. Chapter 20, Unit 20.8.

Boris, S., and Barbes, C. (2000). Role played by lactobacilli in controlling the population of vaginal pathogens. Microbes Infect. 2, 543-546.

Bos, M. P., Grunert, F., and Belland, R. J. (1997). Differential recognition of members of the carcinoembryonic antigen family by Opa variants of Neisseria gonorrhoeae. Infect. Immun. 65, 2353-2361.

Bozja, J., Yi, K., Shafer, W. M., and Stojiljkovic, I. (2004). Porphyrinbased compounds exert antibacterial action against the sexually transmitted pathogens Neisseria gonorrhoeae and Haemophilus ducreyi. Int. J. Antimicrob. Agents 24, 578-584.

Braude, A. I. (1982). Maxwell Finland lecture. Resistance to infection with the gonococcus. J. Infect. Dis. 145, 623-624.

Canny, G.O., Trifonova, R.T., Kindelberger, D. W., Colgan, S. P., and Fichorova, R. N. (2006). Expression and function of bactericidal/permeability-increasing protein in human genital tract epithelial cells. J. Infect. Dis. 194, 498-502.

Carson, S. D., Klebba, P. E., Newton, S. M., and Sparling, P. F. (1999). Ferric enterobactin binding and utilization by Neisseria gonorrhoeae. J. Bacteriol. 181, 2895-2901.

Casey, S. G., Shafer, W.M., and Spitznagel, J. K. (1986). Neisseria gonorrhoeae survive intraleukocytic oxygen-independent antimicrobial capacities of anaerobic and aerobic granulocytes in the presence of pyocin lethal for extracellular gonococci. Infect. Immun. 52, 384-389.

Casey, S. G., Veale, D. R., and Smith, H. (1979).Demonstration of intracellular growth of gonococci in human phagocytes using spectinomycin to kill extracellular organisms. J. Gen. Microbiol. 113, 395-398.

Cohen, M. S., Hoffman, I. F., Royce, R. A., Kazembe, P., Dyer, J. R., Daly, C. C., Zimba, D., Vernazza, P. L., Maida, M., Fiscus, S. A., and Eron, J. J. Jr. (1997). Reduction of concentration of HIV-1 in semen after treatment of urethritis: implications for prevention of sexual transmission of HIV-1. AIDSCAP Malawi Research Group. Lancet 349, 1868-1873.

Cole, J. G., Fulcher, N. B., and Jerse, A. E. (2010). Opacity proteins increase Neisseria gonorrhoeae fitness in the female genital tract due to a factor under ovarian control. Infect. Immun. 78, 1629-1641.

Cone, R. A., Hoen, T., Wong, X., Abusuwwa, R., Anderson, D. J., and Moench, T. R. (2006). Vaginal microbicides: detecting toxicities in vivo that paradoxically increase pathogen transmission. BMC Infect. Dis. 6, 90. doi: 10.1186/1471-2334-6-90

Corbeil, L. B., Chatterjee, A., Foresman, L., and Westfall, J. A. (1985). Ultrastructure of cyclic changes in the murine uterus, cervix, and vagina. Tissue Cell 17, 53-68.

Cornelissen, C. N., Kelley, M., Hobbs, M. M., Anderson, J. E., Cannon, J. G. Cohen, M. S., and Sparling, P.F. (1998). The transferrin receptor expressed by gonococcal strain FA1090 is required for the experimental infection of human male volunteers. Mol. Microbiol. 27, 611-616.

Criss, A. K., Katz, B. Z., and Seifert, H. S. (2009). Resistance of Neisseria gonorrhoeae to non-oxidative killing by adherent human polymorphonuclear leucocytes. Cell. Microbiol. 11, 1074-1087.

Criss, A. K., and Seifert, H. S. (2008). Neisseria gonorrhoeae suppresses the oxidative burst of human polymorphonuclear leukocytes. Cell. Microbiol. 10, 2257-2270.

Dalal, S. J., Estep, J. S., Valentin-Bon, I. E., and Jerse, A.E. (2001). Standardization of the Whitten Effect to induce susceptibility to Neisseria gonorrhoeae in female mice. Contemp. Top. Lab. Anim. Sci. 40, 13-17.

Darville, T., O’Neill, J. M., Andrews, C. W. Jr., Nagarajan, U. M., Stahl, L., and Ojcius, D. M. (2003). Toll-like receptor-2, but not Toll-like receptor-4, is essential for development of oviduct pathology in chlamydial genital tract infection. J. Immunol. 171, 6187-6197.

Douglas, T., Daniel, D. S., Parida, B. K., Jagannath, C., and Dhandayuthapani, S. (2004). Methionine sulfoxide reductase A (MsrA) deficiency affects the survival of Mycobacterium smegmatis within macrophages. J. Bacteriol. 186, 3590-3598.

Draper, D. L., James, J. F., Brooks, G. F., and Sweet, R. L. (1980). Comparison of virulence markers of peritoneal and fallopian tube isolates with endocervical Neisseria gonorrhoeae isolates from women with acute salpingitis. Infect. Immun. 27, 882-888.

Dunkelberger, J. R., and Song, W. C. (2010). Complement and its role in innate and adaptive immune responses. Cell Res. 20, 34-50.

Eades-Perner, A. M., van der Putten, H., Hirth, A., Thompson, J., Neumaier, M. von Kleist, S., and Zimmermann, W. (1994). Mice transgenic for the human carcinoembryonic antigen gene maintain its spatiotemporal expression pattern. Cancer Res. 54, 4169-4176.

Eckert, M., Wittmann, I., Rollinghoff, M., Gessner, A., and Schnare, M. (2006). Endotoxin-induced expression of murine bactericidal permeability/ increasing protein is mediated exclusively by toll/IL-1 receptor domaincontaining adaptor inducing IFN-beta-dependent pathways. $J$. Immunol. 176, 522-528.

Edwards, J. L. (2010). Neisseria gonorrhoeae survival during primary human cervical epithelial cell infection requires nitric oxide and is augmented by progesterone. Infect. Immun. 78, 1202-1213.

Edwards, J. L., and Apicella, M. A. (2004). The molecular mechanisms used by Neisseria gonorrhoeae to initiate infection differ between men and women. Clin. Microbiol. Rev. 17, 965-981. [table of contents].

Edwards, J. L., Brown, E. J., Uk-Nham, S., Cannon, J. G., Blake, M. S., and Apicella, M.A. (2002). A co-operative interaction between Neisseria gonorrhoeae and complement receptor 3 mediates infection of primary cervical epithelial cells. Cell. Microbiol. 4 571-584.

Exley, R. M., Wu, H., Shaw, J., Schneider, M. C., Smith, H., Jerse, A. E., and Tang, C. M. (2007). Lactate acquisition promotes successful colonization of the murine genital tract by Neisseria gonorrhoeae. Infect. Immun $75,1318-1324$.

Feinen, B., Jerse, A. E., Gaffen, S. L., and Russell, M. W. (2010). Critical role of Th17 responses in a murine model of Neisseria gonorrhoeaegenital infection. Mucosal Immunol. 3, 312-321.

Fidel, P. L. Jr., Cutright, J., and Steele, C. (2000). Effects of reproductive hormones on experimental vaginal candidiasis. Infect. Immun. 68, 651-657.

Forbes, J. R., and Gros, P. (2001). Divalentmetal transport by NRAMP proteins at the interface of host-pathogen interactions. Trends Microbiol. 9, 397-403.

Frangipane, J. V., and Rest, R. F. (1992). Anaerobic growth of gonococci does not alter their Opa-mediated interactions with human neutrophils. Infect. Immun. 60, 1793-1799.

Furr, P. M., Hetherington, C. M., and Taylor-Robinson, D. (1989). The susceptibility of germ-free, oestradioltreated, mice to Mycoplasma hominis. J. Med. Microbiol. 30, 233-236.

Gagliardi, M. C., Starnino, S., Teloni, R., Mariotti, S., Dal, I. Conte, Di Carlo, A., and Stefanelli, P. (2011). Circulating levels of interleukin-17A and interleukin-23 are increased in patients with gonococcal infection. FEMS Immunol. Med. Microbiol. 61, 129-132.

Gill, M.J., McQuillen, D. P., van Putten,J.P., Wetzler, L. M., Bramley, J., Crooke, H., Parsons, N. J., Cole, J.A., and Smith, H. (1996). Functional characterization of a sialyltransferase-deficient mutant of
Neisseria gonorrhoeae. Infect. Immun. 64, 3374-3378.

Granata, F., Petraroli, A., Boilard, E., Bezzine, S., Bollinger, J., Del Vecchio, L., Gelb, M. H., Lambeau, G., Marone, G., and Triggiani, M. (2005). Activation of cytokine production by secreted phospholipase A2 in human lung macrophages expressing the M-type receptor. J. Immunol. 174 464-474.

Granoff, D. M., Welsch, J. A., and Ram, S. (2009). Binding of complement factor $\mathrm{H}(\mathrm{fH})$ to Neisseria meningitidis is specific for human $\mathrm{fH}$ and inhibits complement activation by rat and rabbit sera. Infect. Immun. 77, 764-769.

Hasty, L. A., Lambris, J. D., Lessey, B. A., Pruksananonda, K., and Lyttle, C. R. (1994). Hormonal regulation of complement components and receptors throughout the menstrual cycle. Am. J. Obstet. Gynecol. 170(1 Pt 1), 168-175.

Hedges, S. R., Mayo, M. S., Kallman, L., Mestecky, J., Hook, E. W. III, and Russell, M. W. (1998). Evaluation of immunoglobulin A1 (IgA1) protease and IgA1 protease-inhibitory activity in human female genital infection with Neisseria gonorrhoeae. Infect. Immun. $66,5826-5832$

Hillier, S. L., Krohn, M. A., Nugent, R. P., and Gibbs, R.S. (1992). Characteristics of three vaginal flora patterns assessed by gram stain among pregnant women. Vaginal infections and prematurity Study Group. Am. J. Obstet. Gynecol. 166, 938-944.

Holmes, K. K., Counts, G. W., and Beaty, H. N. (1971). Disseminated gonococcal infection. Ann. Intern. Med. 74, 979-993.

Hook, E. W. III, and Holmes, K. K. (1985). Gonococcal infections. Ann. Intern. Med. 102, 229-243.

Hopper, S., Vasquez, B., Merz, A., Clary, S., Wilbur, J. S., and So, M. (2000). Effects of the immunoglobulin A1 protease on Neisseria gonorrhoeae trafficking across polarized T84 epithelial monolayers. Infect. Immun. 68, 906-911.

Imarai, M., Candia, E., Rodriguez-Tirado, C., Tognarelli, J., Pardo, M., Perez, T., Valdes, D., Reyes-Cerpa, S., Nelson, P., Acuna-Castillo, C., and Maisey, K. (2008). Regulatory T cells are locally induced during intravaginal infection of mice with Neisseria gonorrhoeae. Infect. Immun. 76, 5456-5465.

Imtiaz, M. T., Distelhorst, J. T., Schripsema, J. H., Sigar, I. M., Kasimos, J. N., Lacy, S. R., and Ramsey, K. H. (2007). A role for matrix metalloproteinase- 9 in pathogenesis of urogenital Chlamydia muridarum infection in mice. Microbes Infect. 9, 1561-1566.

James, J. F., and Swanson, J. (1978). Studies on gonococcus infection. 
XIIOccurrence of color/opacity colonial variants in clinical cultures. Infect. Immun. 19, 332-340.

Jerse, A. E. (1999). Experimental gonococcal genital tract infection and opacity protein expression in estradiol-treated mice. Infect. Immun. 67, 5699-5708.

Jerse, A. E., Cohen, M. S., Drown, P. M., Whicker, L. G., Isbey, S. F., Seifert, H. S., and Cannon, J. G. (1994). Multiple gonococcal opacity proteins are expressed during experimental urethral infection in the male. J. Exp. Med. 179, 911-920.

Jerse, A. E., Crow, E. T., Bordner, A. N., Rahman, I., Cornelissen, C. N., Moench, T. R., and Mehrazar, K. (2002). Growth of Neisseria gonorrhoeae in the female mouse genital tract does not require the gonococcal transferrin or hemoglobin receptors and may be enhanced by commensal lactobacilli. Infect. Immun. 70, 2549-2558.

Jerse, A. E., Sharma, N. D., Simms, A. N., Crow, E. T., Snyder, L. A., and Shafer, W. M. (2003). A gonococcal efflux pump system enhances bacterial survival in a female mouse model of genital tract infection. Infect. Immun. 71, 5576-5582.

Johannsen, D. B., Johnston, D. M., Koymen, H. O., Cohen, M. S., and Cannon, J. G. (1999). A Neisseria gonorrhoeae immunoglobulin $\mathrm{Al}$ protease mutant is infectious in the human challenge model of urethral infection. Infect. Immun. 67, 3009-3013.

Johansson, L., Rytkonen, A., Bergman, P., Albiger, B., Kallstrom, H., Hokfelt, T., Agerberth, B., Cattaneo, R., and Jonsson, A. B. (2003). CD46 in meningococcal disease. Science 301,373-375.

Johansson, L., Rytkonen, A., Wan, H., Bergman, P., Plant, L., Agerberth, B., Hokfelt, T., and Jonsson, A. B. (2005). Human-like immune responses in CD46 transgenic mice. J. Immunol. 175, 433-440.

Johnson, A. P., Tuffrey, M., and TaylorRobinson, D. (1989). Resistance of mice to genital infection with Neisseria gonorrhoeae. J. Med. Microbiol. 30, 33-36.

Johnson, D. W., Holmes, K. K., Kvale, P. A., Halverson, C. W., and Hirsch, W. P. (1969). An evaluation of gonorrhea case findings in the chronically infected female. Am. J. Epidemiol. 90, 438-448.

Jokimaa, V., Oksjoki, S., Kujari, H., Vuorio, E., and Anttila, L. (2001). Expression patterns of cathepsins $\mathrm{B}, \mathrm{H}, \mathrm{K}, \mathrm{L}$ and $\mathrm{S}$ in the human endometrium. Mol. Hum. Reprod. 7, 73-78.

Kallstrom, H., Blackmer Gill, D., Albiger, B., Liszewski, M. K., Atkinson, J. P., and Jonsson, A. B. (2001). Attachment of Neisseria gonorrhoeae to the cellular pilus receptor $\mathrm{CD} 46$ : identification of domains important for bacterial adherence. Cell. Microbiol. 3, 133-143.

Kallstrom, H., M. Liszewski, K., Atkinson, J. P., and Jonsson, A. B. (1997). Membrane cofactor protein (MCP or CD46) is a cellular pilus receptor for pathogenic Neisseria. Mol. Microbiol. 25, 639-647.

Katz, J., Sambandam, V., Wu, J. H., Michalek, S. M., and Balkovetz, D. F. (2000). Characterization of Porphyromonas gingivalis-induced degradation of epithelial cell junctional complexes. Infect. Immun. 68, 1441-1449.

Kellogg, D. S. Jr., Peacock, W. L. Jr., Deacon, W. E., Brown, L., and Pirkle, D. I. (1963). Neisseria Gonorrhoeae. Virulence, I. Genetically linked to clonal variation. J. Bacteriol. 85 , 1274-1279.

Kennedy, B. P., Payette, P., Mudgett, J., Vadas, P., Pruzanski, W., Kwan, M., Tang, C., Rancourt, D. E., and Cromlish, W. A. (1995). A natural disruption of the secretory group II phospholipase A2 gene in inbred mouse strains. J. Biol. Chem. 270, 22378-22385.

Khan, K. S., Wojdyla, D., Say, L., Gulmezoglu, A. M., and Van Look, P. F. (2006). WHO analysis of causes of maternal death: a systematic review. Lancet 367, 1066-1074.

Kobayashi, S. D., Voyich, J. M., Burlak, C., and DeLeo, F. R. (2005). Neutrophils in the innate immune response. Arch. Immunol. Ther. Exp. (Warsz.) 53, 505-517.

Koch, M. L. (1947). A study of cervical cultures taken in cases of acute gonorrhea with special reference to the phases of the menstrual cycle. Am. J. Obstet. Gynecol. 54, 861-866.

Kolls, J. K., McCray, P. B. Jr., and Chan, Y. R. (2008). Cytokine-mediated regulation of antimicrobial proteins. Nat. Rev. Immunol. 8, 829-835.

Komp Lindgren, P., Marcusson, L. L., Sandvang, D., Frimodt-Moller, N., and Hughes, D. (2005). Biological cost of single and multiple norfloxacin resistance mutations in Escherichia coli implicated in urinary tract infections. Antimicrob. Agents Chemother. 49, 2343-2351.

Kudo, I., and Murakami, M. (2002). Phospholipase A2 enzymes. Prostaglandins Other Lipid Mediat. 68-69, 3-58.

Kuhlewein, C., Rechner, C., Meyer, T. F., and Rudel, T. (2006). Low-phosphatedependent invasion resembles a general way for Neisseria gonorrhoeae to enter host cells. Infect. Immun. 74, 4266-4273.

Lee, B. C., and Schryvers, A. B. (1988). Specificity of the lactoferrin and transferrin receptors in Neisseria gonorrhoeae. Mol. Microbiol. 2, 827-829.

Lee, E. H., and Shafer, W. M. (1999). The farAB-encoded efflux pump mediates resistance of gonococci to longchained antibacterial fatty acids. Mol. Microbiol. 33, 839-845.

Lee, S. W., Bonnah, R. A., Higashi, D. L., Atkinson, J. P., Milgram, S. L., and So, M. (2002). CD46 is phosphorylated at tyrosine 354 upon infection of epithelial cells by Neisseria gonorrhoeae. J. Cell Biol. 156, 951-957.

Lewis, D. A. (2010). The Gonococcus fights back: is this time a knock out? Sex. Transm. Infect. 86, 415-421.

Li, S. H., Huang, H. L., and Chen, Y. H. (2002). Ovarian steroid-regulated synthesis and secretion of complement $\mathrm{C} 3$ and factor B in mouse endometrium during the natural estrous cycle and pregnancy period. Biol. Reprod. 66 322-332.

Lim, K. H., Jones, C. E., vanden Hoven, R. N., Edwards, J. L., Falsetta, M. L. Apicella, M. A., Jennings, M. P., and McEwan, A. G. (2008). Metal binding specificity of the MntABC permease of Neisseria gonorrhoeae and its influence on bacterial growth and interaction with cervical epithelial cells. Infect Immun. 76, 3569-3576.

Lin, L., Ayala, P., Larson, J., Mulks, M., Fukuda, M., Carlsson, S. R., Enns, C., and So, M. (1997). The Neisseria type 2 IgA1 protease cleaves LAMP1 and promotes survival of bacteria within epithelial cells. Mol. Microbiol. 24 1083-1094.

Lorenzen, D. R., Dux, F., Wolk, U., Tsirpouchtsidis, A., Haas, G., and Meyer, T. F. (1999). Immunoglobulin Al protease, an exoenzyme of pathogenic Neisseriae, is a potent inducer of proinflammatory cytokines. J. Exp. Med. 190, 1049-1058.

Lorenzen, D. R., Gunther, D., Pandit, J., Rudel, T., Brandt, E., and Meyer, T. F. (2000). Neisseria gonorrhoeae porin modifies the oxidative burst of human professional phagocytes. Infect. Immun. 68, 6215-6222.

Madico, G., Ngampasutadol, J., Gulati, S., Vogel, U., Rice, P. A., and Ram, S. (2007). Factor $\mathrm{H}$ binding and function in sialylated pathogenic Neisseriae is influenced by gonococcal, but not meningococcal, porin. J. Immunol. $178,4489-4497$.

Martin, H. L., Richardson, B. A., Nyange, P. M., Lavreys, L., Hillier, S. L., Chohan, B., Mandaliya, K., Ndinya-Achola,J. O., Bwayo, J., and Kreiss, J. (1999). Vaginal lactobacilli, microbial flora, and risk of human immunodeficiency virus type 1 and sexually transmitted disease acquisition. J. Infect. Dis. 180, 1863-1868.

McCormack, W. M., and Reynolds, G. H. (1982). Effect of menstrual cycle and method of contraception on recovery of Neisseria gonorrhoeae. JAMA 247, 1292-1294.

McGowin, C. L., Spagnuolo, R. A., and Pyles, R. B. (2009). Mycoplasma genitalium rapidly disseminates to the upper reproductive tracts and knees of female mice following vaginal inoculation. Infect. Immun. 78, 726-736

Mickelsen, P. A., Blackman, E., and Sparling, P. F. (1982). Ability of Neisseria gonorrhoeae, Neisseria meningitidis, and commensal Neisseria species to obtain iron from lactoferrin. Infect. Immun. 35, 915-920.

Miller, W. C., Ford, C. A., Morris, M., Handcock, M. S., Schmitz, J.L., Hobbs, M. M., Cohen, M. S., Harris, K. M., and Udry, J. R. (2004). Prevalence of chlamydial and gonococcal infections among young adults in the United States. JAMA 291, 2229-2236.

Muench, D. F., Kuch, D. J., Wu, H., Begum, A. A., Veit, S. J., Pelletier, M. E., SolerGarcia, A. A., and Jerse, A. E. (2009). Hydrogen peroxide-producing lactobacilli inhibit gonococci in vitro but not during experimental genital tract infection. J. Infect. Dis. 199, 1369-1378.

Muenzner, P., Bachmann, V., Zimmermann, W., Hentschel, J., and Hauck, C. R. (2010). Humanrestricted bacterial pathogens block shedding of epithelial cells by stimulating integrin activation. Science 329, 1197-1201.

Muenzner, P., Rohde, M., Kneitz, S., and Hauck, C. R. (2005). CEACAM engagement by human pathogens enhances cell adhesion and counteracts bacteriainduced detachment of epithelial cells. J. Cell Biol. 170, 825-836.

Naids, F. L., and Rest, R. F. (1991). Stimulation of human neutrophil oxidative metabolism by nonopsonized Neisseria gonorrhoeae. Infect. Immun. 59, 4383-4390.

Ngampasutadol, J., Ram, S., Gulati, S., Agarwal, S., Li, C., Visintin, A., Monks, B., Madico, G., and Rice, P. A. (2008a). Human factor $\mathrm{H}$ interacts selectively with Neisseria gonorrhoeae and results in species-specific complement evasion. J. Immunol. 180, 3426-3435.

Ngampasutadol, J., Tran, C., Gulati, S., Blom, A. M., Jerse, E. A., Ram, S., and Rice, P. A. (2008b). Species-specificity of Neisseria gonorrhoeae infection: do human complement regulators contribute? Vaccine 26(Suppl. 8), I62-I66.

Nizet, V., Ohtake, T., Lauth, X., Trowbridge, J., Rudisill, J., Dorschner, R. A., Pestonjamasp, V., Piraino, J., Huttner, K., and Gallo, R. L. (2001). Innate antimicrobial peptide protects the skin from invasive bacterial infection. Nature 414, 454-457.

Noguchi, K., Tsukumi, K., and Urano, T. (2003). Qualitative and quantitative 
differences in normal vaginal flora of conventionally reared mice, rats, hamsters, rabbits, and dogs. Comp. Med. 53, 404-412.

Nsuami, M., Cammarata, C. L., Brooks, B. N., Taylor, S. N., and Martin, D. H. (2004). Chlamydia and gonorrhea cooccurrence in a high school population. Sex. Transm. Dis. 31, 424-427.

O’Hanlon, D. E., Lanier, B. R., Moench, T. R., and Cone, R. A. (2010). Cervicovaginal fluid and semen block the microbicidal activity of hydrogen peroxide produced by vaginal lactobacilli. BMC Infect. Dis. 10, 120. doi: 10.1186/1471-2334-10-120

Packiam, M., Veit, S. J., Anderson, D. J., Ingalls, R. R., and Jerse, A. E. (2010). Mouse strain-dependent differences in susceptibility to Neisseria gonorrhoeae infection and induction of innate immune responses. Infect. Immun. $78,433-440$.

Papayannopoulos, V., and Zychlinsky, A. (2009). NETs: a new strategy for using old weapons. Trends Immunol. 30, 513-521.

Plante, M., Jerse, A., Hamel, J., Couture, F., Rioux, C. R., Brodeur, B. R., and Martin, D. (2000). Intranasal immunization with gonococcal outer membrane preparations reduces the duration of vaginal colonization of mice by Neisseria gonorrhoeae. J. Infect. Dis. 182, 848-855.

Polissi, A., Pontiggia, A., Feger, G., Altieri, M., Mottl, H., Ferrari, L., and Simon, D. (1998). Large-scale identification of virulence genes from Streptococcus pneumoniae. Infect. Immun. 66, 5620-5629.

Qiu, J., Brackee, G. P., and Plaut, A. G. (1996). Analysis of the specificity of bacterial immunoglobulin A (IgA) proteases by a comparative study of ape serum IgAs as substrates. Infect. Immun. 64, 933-937.

Ram, S., Cullinane, M., Blom, A. M., Gulati, S., McQuillen, D. P., Monks, B. G., O'Connell, C., Boden, R., Elkins, C., Pangburn, M. K., Dahlback, B., and Rice, P.A. (2001). Binding of C4bbinding protein to porin: a molecular mechanism of serum resistance of Neisseria gonorrhoeae. J. Exp. Med. 193, 281-295.

Ram, S., McQuillen, D. P., Gulati, S., Elkins, C., Pangburn, M. K., and Rice, P. A. (1998). Binding of complement factor $\mathrm{H}$ to loop 5 of porin protein 1A: a molecular mechanism of serum resistance of nonsialylated Neisseria gonorrhoeae. J. Exp. Med. 188, 671-680.

Ramjee, G., Kamali, A., and McCormack, S. (2010). The last decade of microbicide clinical trials in Africa: from hypothesis to facts. AIDS 24(Suppl. 4), S40-9.
Rausch, P. G., and Moore, T. G. (1975). Granule enzymes of polymorphonuclear neutrophils: a phylogenetic comparison. Blood 46, 913-919.

Rechner, C., Kuhlewein, C., Muller, A., Schild, H., and Rudel, T. (2007). Host glycoprotein Gp96 and scavenger receptor SREC interact with PorB of disseminating Neisseria gonorrhoeae in an epithelial invasion pathway. Cell Host Microbe 2, 393-403.

Rest, R. F., Fischer, S. H., Ingham, Z. Z., and Jones, J. F. (1982). Interactions of Neisseria gonorrhoeae with human neutrophils: effects of serum and gonococcal opacity on phagocyte killing and chemiluminescence. Infect. Immun. 36, 737-744.

Rosenvinge, M. M., and Lau, R. (2009). Screening for asymptomatic chlamydia in women - how often would gonorrhoea be missed? Int. J. STD AIDS 20, 571-572.

Russell, M. W., and Hook, E. W. (2008). "Gonorrhea," in Vaccines for Biodefense and Emerging and Neglected Diseases, eds A. D. T. Barrett and L. R. Stanberry (Amsterdam: Elsevier), 953-972.

Sadarangani, M., Pollard, A. J., and GrayOwen, S. D. (2011). Opa proteins and CEACAMs: pathways of immune engagement for pathogenic Neisseria. FEMS Microbiol. Rev. 35, 488-514.

Saigh, J. H., Sanders, C. C., and Sanders, W.E. Jr. (1978). Inhibition of Neisseria gonorrhoeae by aerobic and facultatively anaerobic components of the endocervical flora: evidence for a protective effect against infection. Infect. Immun. 19, 704-710.

Schryvers, A. B., and Stojiljkovic, I. (1999). Iron acquisition systems in the pathogenic Neisseria. Mol. Microbiol. 32, 1117-1123.

Seib, K. L., Simons, M. P., Wu, H. J., McEwan, A. G., Nauseef, W. M., Apicella, M. A., and Jennings, M. P. (2005). Investigation of oxidative stress defenses of Neisseria gonorrhoeae by using a human polymorphonuclear leukocyte survival assay. Infect. Immun. 73, 5269-5272.

Seib, K. L., Wu, H. J., Kidd, S. P., Apicella, M. A., Jennings, M. P., and McEwan, A. G. (2006). Defenses against oxidative stress in Neisseria gonorrhoeae: a system tailored for a challenging environment. Microbiol. Mol. Biol. Rev. 70, 344-361.

Serino, L., Nesta, B., Leuzzi, R., Fontana, M. R., Monaci, E., Mocca, B. T., Cartocci, E., Masignani, V., Jerse, A. E., Rappuoli, R., and Pizza, M. (2007). Identification of a new OmpAlike protein in Neisseria gonorrhoeae involved in the binding to human epithelial cells and in vivo colonization. Mol. Microbiol. 64, 1391-1403.
Shafer, W. M., Veal, W. L., Lee, E. H., Zarantonelli, L., Balthazar, J. T., and Rouquette, C. (2001). Genetic organization and regulation of antimicrobial efflux systems possessed by Neisseria gonorrhoeae and Neisseria meningitidis. J. Mol. Microbiol. Biotechnol. 3, 219-224.

Simms, A. N., and Jerse, A. (2005). "Role of phase and antigenic variation in Neisseria gonorrhoeae colonization," in Colonization of Mucosal Surfaces, ed. J.P.Nataro (Washington, DC: ASM Press), 327-350.

Simms, A. N., and Jerse, A. E. (2006). In vivo selection for Neisseria gonorrhoeae opacity protein expression in the absence of human carcinoembryonic antigen cell adhesion molecules. Infect. Immun. 74, 2965-2974.

Simons, M. P., Nauseef, W. M., and Apicella, M. A. (2005). Interactions of Neisseria gonorrhoeae with adherent polymorphonuclear leukocytes. Infect. Immun. 73, 1971-1977.

Singer, A. (1975). The uterine cervix from adolescence to the menopause. $\mathrm{Br} . \mathrm{J}$. Obstet. Gynaecol. 82, 81-99.

Smith, H., Parsons, N. J., and Cole, J. A. (1995). Sialylation of neisserial lipopolysaccharide: a major influence on pathogenicity. Microb. Pathog. 19, 365-377.

Smith, H., Tang, C. M., and Exley, R. M. (2007). Effect of host lactate on gonococci and meningococci: new concepts on the role of metabolites in pathogenicity. Infect. Immun. 75, 4190-4198.

Soler-Garcia, A. A., and Jerse, A. E. (2007). Neisseria gonorrhoeae catalase is not required for experimental genital tract infection despite the induction of a localized neutrophil response. Infect. Immun. 75, 2225-2233.

Song, W., Condron, S., Mocca, B. T., Veit, S. J., Hill, D., Abbas, A., and Jerse, A. E. (2008). Local and humoral immune responses against primary and repeat Neisseria gonorrhoeae genital tract infections of 17beta-estradiol-treated mice. Vaccine 26, 5741-5751.

Song, W., Ma, L., Chen, R., and Stein, D. C. (2000). Role of lipooligosaccharide in Opa-independent invasion of Neisseria gonorrhoeae into human epithelial cells. J. Exp. Med. 191, 949-960.

Sparling, P. F. (1999). "Biology of Neisseria gonorrhoeae," in Sexually Transmitted Diseases, 3rd Edn, eds K. K. Holmes, P.-A. Mardh, P. F. Sparling, S. M. Lemon, W. E. Stamm, P. Piot, and J. N. Wasserheit (New York: McGrawHill, Inc.), 433-449.

Spencer, S. E., Valentin-Bon, I. E., Whaley, K., and Jerse, A. E. (2004). Inhibition of Neisseria gonorrhoeae genital tract infection by leading-candidate topical microbicides in a mouse model. $J$. Infect. Dis. 189, 410-419.

Spurbeck, R. R., and Arvidson, C. G. (2010). Lactobacillus jensenii surfaceassociated proteins inhibit Neisseria gonorrhoeae adherence to epithelial cells. Infect. Immun. 78, 3103-3111.

St Amant, D. C., Valentin-Bon, I. E., and Jerse, A. E. (2002). Inhibition of Neisseria gonorrhoeae by Lactobacillus species that are commonly isolated from the female genital tract. Infect. Immun. 70, 7169-7171.

St John, G., Brot, N., Ruan, J., ErdjumentBromage, H., Tempst, P., Weissbach, H., and Nathan, C. (2001). Peptide methionine sulfoxide reductase from Escherichia coli and Mycobacterium tuberculosis protects bacteria against oxidative damage from reactive nitrogen intermediates. Proc. Natl. Acad. Sci. U.S.A. 98, 9901-9906.

Stojiljkovic, I., Larson, J., Hwa, V., Anic, S., and So, M. (1996). HmbR outer membrane receptors of pathogenic Neisseria spp.: iron-regulated, hemoglobin-binding proteins with a high level of primary structure conservation. J. Bacteriol. 178, 4670-4678.

Storz, G., Tartaglia, L. A., Farr, S. B., and Ames, B. N. (1990). Bacterial defenses against oxidative stress. Trends Genet. 6, 363-368.

Strange, H.R., Zola, T.A., and Cornelissen, C. N. (2010). The fbpABC operon is required for ton-independent utilization of xenosiderophores by Neisseria gonorrhoeae strain FA19. Infect. Immun. 79, 267-278.

Straub, R. H. (2007). The complex role of estrogens in inflammation. Endocr. Rev. 28, 521-574.

Streeter, P. R., and Corbeil, L. B. (1981). Gonococcal infection in endotoxinresistant and endotoxin-susceptible mice. Infect. Immun. 32, 105-110.

Swanson, J., Barrera, O., Sola, J., and Boslego, J. (1988). Expression of outer membrane protein II by gonococci in experimental gonorrhea. J. Exp. Med. 168, 2121-2129.

Swanson, K. V., Jarvis, G. A., Brooks, G. F., Barham, B. J., Cooper, M. D., and Griffiss, J. M. (2001). CEACAM is not necessary for Neisseria gonorrhoeae to adhere to and invade female genital epithelial cells. Cell. Microbiol. 3, 681-691.

Tapsall, J.W. (2009). Neisseria gonorrhoeae and emerging resistance to extended spectrum cephalosporins. Curr. Opin. Infect. Dis. 22, 87-91.

Tapsall, J. W., Limnios, E. A., Nguyen, N. L., Carter, I., Lum, G., Freeman, K., Tabrizi, S. N., Garland, S. M., Whiley, D. M., Sloots, T. P., and Chambers, I. W. (2005). Cryptic-plasmid-free gonococci may contribute to failure 
of cppB gene-based assays to confirm results of BD ProbeTEC PCR for identification of Neisseria gonorrhoeae. J. Clin. Microbiol. 43, 2036-2037.

Taylor-Robinson, D., Furr, P. M., and Hetherington, C. M. (1990). Neisseria gonorrhoeae colonises the genital tract of oestradiol-treated germ-free female mice. Microb. Pathog. 9, 369-373.

The Carraguard Phase II South Africa Study Team. (2010). Expanded safety and acceptability of the candidate vaginal microbicide Carraguard(R) in South Africa. Contraception 82, 563-571.

van Putten, J. P., Duensing, T. D., and Carlson, J. (1998). Gonococcal invasion of epithelial cells driven by P.IA, a bacterial ion channel with GTP binding properties. J. Exp. Med. 188, 941-952.

von Mollendorf, C. E., Van Damme, L., Moyes, J. A., Rees, V. H., Callahan, M. M., Mauck, C. K., Puren, A. J., Tweedy, K., and Taylor, D. (2010). Results of a safety and feasibility study of the diaphragm used with ACIDFORM Gel or K-Y Jelly. Contraception 81, 232-239.

Vonck, R. A., Darville, T., O'Connell, C. M., and Jerse, A. E. (2011). Chlamydial infection increases gonococcal colonization in a novel murine coinfection model. Infect. Immun. 79, 1566-1577.

Warner, D. M., Folster, J. P., Shafer, W. M., and Jerse, A. E. (2007). Regulation of the MtrC-MtrD-MtrE efflux-pump system modulates the in vivo fitness of Neisseria gonorrhoeae. J. Infect. Dis. 196, 1804-1812.

Warner, D. M., Shafer, W. M., and Jerse, A.E. (2008). Clinically relevant mutations that cause derepression of the Neisseria gonorrhoeae MtrC-MtrDMtrE Efflux pump system confer different levels of antimicrobial resistance and in vivo fitness. Mol. Microbiol. 70, 462-478.

Weyand, N. J., Calton, C. M., Higashi, D. L., Kanack, K. J., and So, M. (2009). Presenilin/gamma-secretase cleaves CD46 in response to Neisseria infection. J. Immunol. 184, 694-701.

Wiesenfeld, H. C., Hillier, S. L., Krohn, M. A., Landers, D. V., and Sweet, R. L. (2003). Bacterial vaginosis is a strong predictor of Neisseria gonorrhoeae and Chlamydia trachomatisinfection. Clin. Infect. Dis. 36, 663-668.

$\mathrm{Wu}$, H., and Jerse, A. E. (2006). Alpha2,3-sialyltransferase enhances Neisseria gonorrhoeae survival during experimental murine genital tract infection. Infect. Immun. 74, 4094-4103.

Wu, H., Soler-Garcia, A. A., and Jerse, A. E. (2009). A strain-specific catalase mutation and mutation of the metal-binding transporter gene $\mathrm{mntC}$ attenuate Neisseria gonorrhoeae in vivo but not by increasing susceptibility to oxidative killing by phagocytes. Infect. Immun. 77, 1091-1102.

Yao, X. D., Fernandez, S., Kelly, M. M., Kaushic, C., and Rosenthal, K. L. (2007). Expression of Toll-like receptors in murine vaginal epithelium is affected by the estrous cycle and stromal cells. J. Reprod. Immunol. 75, 106-119.

Zarantonelli, M.L., Szatanik, M., Giorgini, D., Hong, E., Huerre, M., Guillou, F. Alonso, J. M., and Taha, M. K. (2007). Transgenic mice expressing human transferrin as a model for meningococcal infection. Infect. Immun. 75 5609-5614.

Zeitlin, L., Hoen, T. E., Achilles, S. L., Hegarty, T. A., Jerse, A. E., Kreider, J. W., Olmsted, S. S., Whaley, K. J., Cone, R. A., and Moench, T. R. (2001). Tests of Buffergel for contraception and prevention of sexually transmitted diseases in animal models. Sex. Transm. Dis. 28, 417-423.
Zhu, W., Chen, C.-J., Thomas, C. E. Anderson, J. E., Jerse, A. E., and Sparling, P. F. (2011). Vaccines for gonorrhea: can we rise the the challenge? Front. Microbiol. 2, 1-23.

Conflict of Interest Statement: The authors declare that the research was conducted in the absence of any commercial or financial relationships that could be construed as a potential conflict of interest.

Received: 16 February 2011; paper pending published: 08 March 2011; accepted: 28 April 2011; published online: 01 July 2011. Citation: Jerse AE, Wu H, Packiam M, Vonck RA, Begum AA and Garvin LE (2011) Estradiol-treated female mice as surrogate hosts for Neisseria gonorrhoeae genital tract infections. Front. Microbio. 2:107. doi: 10.3389/fmicb.2011.00107 This article was submitted to Frontiers in Cellular and Infection Microbiology, a specialty of Frontiers in Microbiology.

Copyright (c) Jerse, Wu, Packiam, Vonck, Begum and Garvin. This is an open-access article subject to a non-exclusive license between the authors and Frontiers Media $S A$, which permits use, distribution and reproduction in other forums, provided the original authors and source are credited and other Frontiers conditions are complied with. 